\title{
CAMINOS DE ACCESO AL USUFRUCTO Y PROPIEDAD LEGAL DE LA TIERRA EN LA FRONTERA BONAERENSE. DOLORES, 1798-1860.
}

\author{
Alejandra R. Mascioli ${ }^{*}$
}

El mundo rural rioplatense de la primera mitad del siglo XIX presenta características que habrían sido insospechadas años atrás. Un número cada vez mayor de investigaciones está dando cuenta de las mismas a partir del análisis de aspectos tanto socio-económicos como demográficos y políticos.

Continuidades y rupturas, respecto a la etapa colonial tardía, caracterizan este período. Entre las primeras hallamos la persistencia del crecimiento demográfico a partir tanto del incremento vegetativo como del aporte de las migraciones procedentes de Buenos Aires y su campaña, del interior de lo que fuera el Virreinato del Río de la Plata y del exterior. Asimismo, junto a la creciente producción vacuna y ovina, la agricultura persiste. Tanto el mercado ultramarino como los de la ciudad de Buenos Aires y los de los pueblos de la campaña siguen siendo sitios en los que desemboca esta producción. Y, ya sea en áreas de antigua como de más reciente colonización, encontramos explotaciones de diverso tipo y tamaño, en las que la presencia de familias y de mano de obra libre y forzada sigue siendo un hecho. Del lado de las rupturas, es posible señalar el surgimiento de un grupo de grandes productores y propietarios y la creciente consolidación del Estado provincial, con las particularidades inherentes a los intentos de implementación de una nueva normativi-

\footnotetext{
* Consejo Nacional de Investigaciones Científicas y Técnicas, Grupo de Investigación en Historia Rural Rioplatense de la Facultad de Humanidades de la Universidad Nacional de Mar del Plata. Este trabajo forma parte de la Tesis de Maestría titulada Propietarios y productores de la frontera bonaerense, 1798-1860, presentada en la Universidad Internacional de Andalucía, Sede Iberoamericana Santa María de La Rábida, España, en diciembre de 1999.
} 
dad'.

El objetivo de nuestro trabajo es contribuir a esta caracterización a partir del análisis del proceso colonizador de un área al sur del río Salado de la actual provincia de Buenos Aires en la primera mitad del siglo XIX. Para ello circunscribimos espacial y temporalmente nuestro estudio al partido de Dolores (más amplio territorialmente que el actual, como ya veremos), entre 1798 y 1860 . La caracterización del proceso de acceso al usufructo y a la propiedad legal de la tierra en la zona, de que tratan las páginas que siguen, sumado al análisis socio-demográfico de la población, que realizáramos en otra oportunidad, aspiran a ser un aporte en ese sentido ${ }^{2}$.

Lejos de constituir el caso estudiado un ejemplo paradigmático de la "expansión ganadera" operada en el marco de grandes latifundios en poder de unos pocos propietarios (imagen tal vez esperable al referirnos a un área al sur del Salado y en pleno proceso de colonización entre fines del siglo XVIII y principios del XIX), la complejidad y el dinamismo del proceso estudiado quedan en evidencia: usufructuar y apropiarse legalmente de la tierra en Dolores supone el posible tránsito, de productores con posibilidades y necesidades diferentes, a través de diversos caminos.

La reconstrucción del proceso desde 1798 (fecha de los primeros asentamientos de que tenemos información), hasta pasado mediados de siglo, nos permite hacer comparaciones con los ocurridos en otras zonas y en otros momentos, contribuyendo así a explicar la ocupación del espacio pampeano en una perspectiva diacrónica.

\section{Las fuentes}

La reconstrucción del proceso de acceso a la tierra podría compararse al armando de un rompecabezas: hay que ir engarzando cuidadosamente cada una de las piezas que lo forman. Estas múltiples "piezas", a su vez, provienen de variados repositorios históricos. Así, entre las fuentes que utilizamos en la realización de este trabajo se encuentran las Mensuras Antiguas al sur del Salado, los Duplicados de Mensuras de los partidos de Dolores, Castelli, Pila, Tordillo, General Guido y General Lavalle, el Libro de Enfiteusis $1825-1840$ y el Registro de Arrendamientos y enfiteusis-ventas 1818-1838 que se hallan en el Archivo Histórico de Geodesia y Catastro de la ciudad de La Plata (en adelante AHGyC). Consultamos, asimismo, varios Legajos de la Sección Escribanía Mayor de Gobierno del Archivo Histórico de la provincia de Buenos Aires (en adelante AHPBA), también en La Plata. De fundamental importancia resulta, a su vez, el material cartográfico trabajado proveniente del

1 Con relación a algunas investigaciones recientes que complejizan la caracterización del mundo rural rioplatense en la primera mitad del siglo XIX ver, entre otros, AA.VV., 1997: 12-173. 
AHGyC. Entre éste se encuentran los planos de los terrenos contenidos en las Mensuras Antiguas y en los Duplicados de Mensuras, el plano general de mensuras del partido de Dolores, los Registros Gráficos de la provincia de Buenos Aires de 1833 y 1864 y un plano de los 27 partidos al exterior del Salado según decreto de $1865^{3}$.

\section{El partido de Dolores}

El proceso colonizador al sur del río Salado de la provincia de Buenos Aires se habría iniciado entre fines del siglo XVIII y las primeras décadas del siglo XIX cuando algunos colonos deciden afincarse en la zona, instalando allí sus establecimientos productivos.

Bajo la conducción de Juan Martín de Pueyrredón como Director Supremo de las Provincias Unidas del Río de La Plata (entre 1816 y 1819) se lleva a cabo un avance "formal" hacia el sur y el oeste de lo que luego sería la provincia de Buenos Aires, traspasando el río Salado que oficiara hasta entonces como límite natural entre las sociedades "blanca" e indígena ${ }^{4}$.

En este avance se concreta la fundación del primer pueblo ubicado al sur del Salado. En 1817, en un ejido de tres cuartas leguas de frente por dos de fondo, ubicado entre las tierras de Julián Martínez de Carmona y Miguel González Salomón en las inmediaciones de los Montes del Tordillo, se crea el curato de Nuestra Señora de los Dolores (al frente del cual está el Presbítero Francisco José de Paula Robles) y la Comandancia Militar y Política de las Islas del Tordillo (ejercida por Pedro Antonio Paz). Un año más tarde tiene lugar la fundación del pueblo de Dolores $^{5}$.

Dolores, apócope derivado de la advocación de la virgen María como Nuestra Señora de los Siete Dolores es, hasta la fijación de los límites actuales del partido en 1865, objeto de cambios respecto a la extensión de su territorio y a la correspondiente jurisdicción de sus autoridades. Así, en un principio se halla bajo la jurisdicción de los Alcaldes de Hermandad y Tenientes del Fuerte de Nuestra Señora de la Merced de Chascomús, quedando después adscripto al partido de Monsalvo al crearse éste entre 1821 y 1825 . Recién a partir de 1831 comienza a existir como partido, con el establecimiento de un Juzgado de Paz propio. A éste se añade, en 1856, la autoridad ejercida por la Municipalidad.

Antes de su constitución como partido, el pueblo de Dolores es "refunda-

3 Para una descripción detallada de la información que brinda cada uno de los tipos de fuentes consultadas, como así también de la manera en que las fuimos trabajando, remitimos al lecior al apéndice al final del trabajo.

4 Para una explicación detallada respecto a los procesos operados en áreas de frontera y especialmente en la que aqui nos ocupa, remitimos a Mascioli, 1999: 8-20 (mimeo).

5 Roncoroni, $1967: 28-48$. Según este autor, el pueblo habría sido fundado por Ramón Lara en el sitio elegido por Pedro Antonio Paz. Desde el punto de vista de Rolando Dorcas Berro, en cambio, este último habría sido el fundador, mientras que el primero sólo habría participado en la "refundación" del poblado en el año 1826. Dorcas Berro, $1939: 1-42$. 
do" en 1826 por iniciativa de Ramón Lara (acompañado por el Padre Ramón González) a raíz de la "destrucción" sufrida en 1821 (y probablemente también en 1823) por la incursión de malones indígenas. En 1839, tras el levantamiento conocido como Revolución del Sur, en el que tienen activa participación los pobladores de Chascomús y Dolores, el gobernador de la provincia de Buenos Aires Juan Manuel de Rosas (1829-1832; 1835-1852) decide dividir a este último partido en otros tres: Dolores, Pila y Tordillo. De acuerdo a lo expuesto en el decreto del 25 de diciembre de 1839, por el que se rige tal división, antes de esa fecha el partido de Dolores abarcaría una amplia superficie hoy comprendida por Dolores, Castelli, Tordillo, parte de Pila, parte de General Guido y parte de General Lavalle (Ver mapa 1).

MAPA 1 - Partido de Dolores. Limites anteriores a 1839 y actuales.

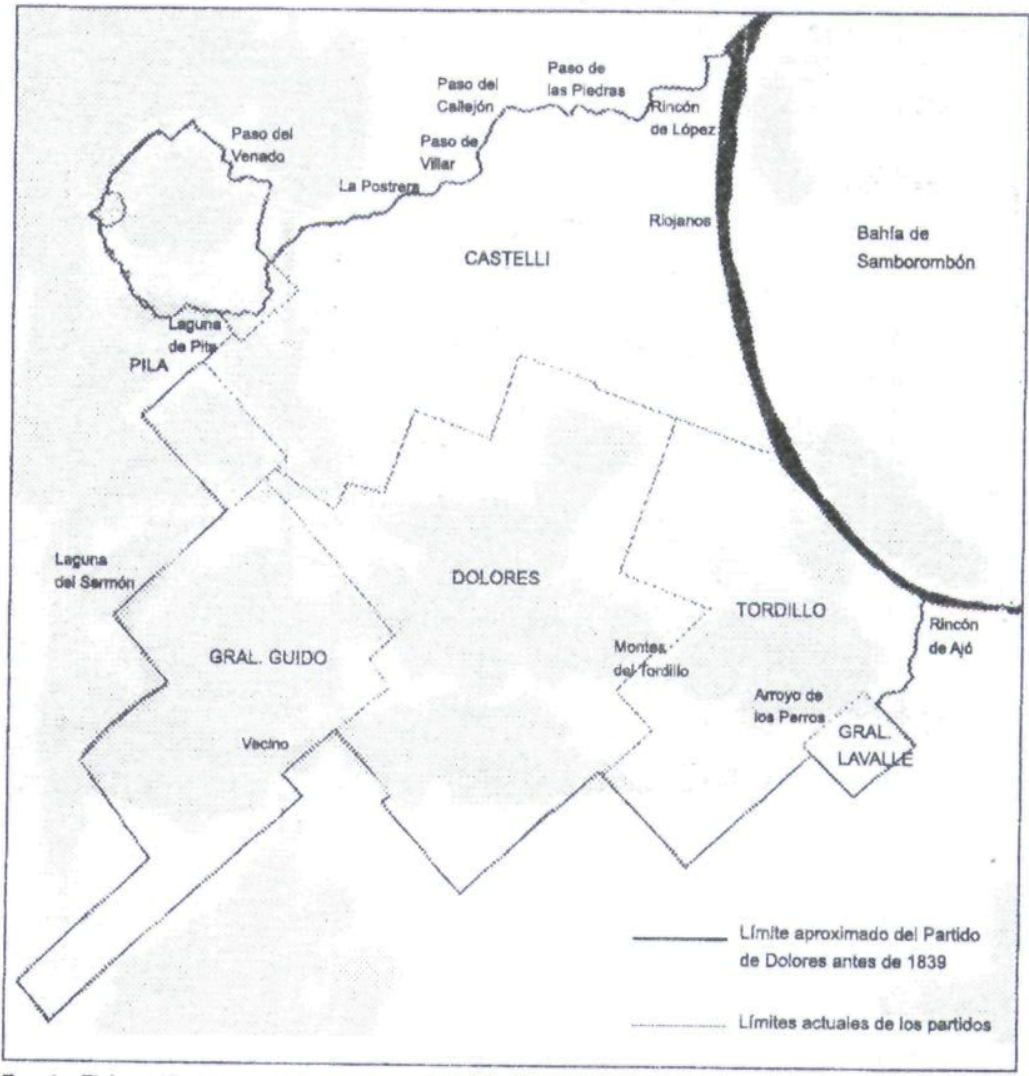

Fuente: Elaboración propia en base a Duplicados de Mensuras de los partidos de Dolores, Castelil, Tordilio, Pila, Gral. Lavalle y Gral. Guido; Mensuras Antiguas al sur del Salado; Registro Gráfico de la Provincia de Buenos Aires de 1864 (AHGyC); Legajos varios de la sección Escribania Mayor de Gobierno (AHPBA). 


\section{Algunas características de la población}

En el marco de un sostenido crecimiento de población tanto en la ciudad como en la campaña de Buenos Aires entre 1838 y $1854 / 55$ (a tasas del 1,9\% y $4,2 \%$ anual respectivamente), Dolores ve incrementar el número de sus habitantes durante la primera mitad del siglo XIX $\mathrm{X}^{6}$. Así, mientras en 1836 hay registrados en el área 2.757 individuos, dos años más tarde éstos ascienden a 2.803, en 1854 a 8.490 y, hacia 1858 a $9.608^{7}$.

El análisis de la población de Dolores a partir de los censos de 1836, 1838 y del resumen de 1854 nos indica que se trata mayormente de individuos considerados blancos, provenientes tanto de las distintas zonas de lo que fuera posteriormente territorio argentino como del exterior, con un índice de masculinidad de algo más de 120 (aunque elevado no es éste el mayor hallado hasta el momento para la campaña de Buenos Aires), que se reparte entre el pueblo de Dolores, las quintas y chacras de sus inmediaciones y las estancias más alejadas.

El hecho de que el desequilibrio entre los sexos no sea tan marcado como podría suponerse al tratarse de una zona de frontera, sumado a aquel otro que nos indica que al menos el $80 \%$ de las personas se hallan vinculadas por lazos de parentesco, como pudimos ver en un trabajo anterior, pone en evidencia que esta sociedad está constituida por "familias" y no por individuos "solos".

Esta conformación social, en la que el $77 \%$ de las unidades censales que corresponden a quintas, chacras y estancias tienen registrada alguna familia, está sin duda imbricada con el proceso productivo del lugar. Así planteamos en otra oportunidad que el $50 \%$ de las mismas habría asumido las tareas productivas utilizando preferentemente la mano de obra aportada por dicha familia; el $27 \%$ se hallaría comprendido por aquellas que suman trabajadores a su familia contratando mano de obra externa; por último, el 13\% de las unidades censales registran sólo trabajadores externos al momento del censo de 1.836 (peones, esclavos, capataces, mayordomos, conchabados, entre otros).

Con relación a aquel sector de los que poseen mano de obra externa (excluyendo de ésta a los agregados) planteamos que mientras muchos productores controlan poca mano de obra, unos pocos tienen mucha. Así, el $72,5 \%$ de los productores posee el $36 \%$ de los trabajadores externos (en número de entre 1 y 2 por establecimiento), el $20 \%$ de los mismos tiene el $30 \%$ de la mano de obra externa

6 Mateo, $1999: 149$.

7 De acuerdo a los datos de que disponemos, la tasa de crecimiento poblacional en Dolores, entre 1836 y 1858 , es del 5,8\% anual omitiendo considerar, sin embargo, los reajustes territoriales posteriores a 1839.

8 Con relación a los individuos no relacionados explícitamente por lazos de parentesco en $1836(20 \%$ del total de quienes tienen algún tipo de relación consignada), es posible que al menos algunos estén emparentados con miembros de otras unidades censales. Si tenemos en cuenta esta posibilidad, como así también la de la existencia de parentesco de tipo espiritual (es decir, aquel que contrae con los padres el padrino de bautismo de una criatura), la proporción de individuos "solos" se reduciría. Para un mayor detalle de estas cuestiones remitimos a Mascioli, $1999: 185-209$. 
(poseyendo entre 3 y 5 trabajadores por establecimiento) y una proporción menor, compuesta por el 7,5\% de los productores, controla nada menos que el $34 \%$ de los trabajadores externos (en cantidades de entre 6 y 16 por establecimiento).

La complejidad de la organización social del partido de Dolores en la primera mitad del siglo XIX dista de aquella imagen de un territorio conformado únicamente por grandes estancias habitadas por "patrones y peones". Estamos, por el contrario, en presencia de productores con distintas posibilidades y necesidades con relación al empleo de mano de obra. Profundicemos entonces su caracterización a partir del análisis del proceso de acceso al usufructo y apropiación legal de la tierra en la zona.

\section{El acceso a la tierra en la frontera}

Acceder a la propiedad de la tierra en la zona de frontera que nos ocupa, entre 1798 y 1860, supone la posibilidad de transitar por diversos caminos. En el transcurso de los mismos podemos distinguir, de un lado, el acceso al usufructo de la tierra (de hecho o por derecho) y, del otro, la apropiación legal.

A lo largo del período analizado hay en Dolores una oferta estatal de tierras públicas (realengas hacia fines del siglo XVIII y la primera década del XIX) cuyos derechos de propiedad y/o usufructo van siendo entregados a muchos de quienes presentan solicitudes?. De esta manera, entre las décadas de 1790 y 1830 el Estado adjudica tierras directamente en propiedad a través de ventas, concesiones de merced, moderada composición, donaciones y otorgamientos por "gracia del gobierno $^{\prime 10}$. Asimismo, durante las décadas de 1820 y 1830 concede el derecho al usufructo de las mismas bajo la forma de la enfiteusis" $y$, en la de 1850, del arrendamiento ${ }^{12}$. Las tierras obtenidas bajo estas dos últimas modalidades podían ser luego compradas al Estado, ya sea por quienes las habían obtenido de éste o por aque-

9 Se denominan tierras realengas a aquellas cuyo dominio, por derecho de conquista, corresponde a la Corona castellana. (Ots Capdequi, 1945: 273-292).

$10 \mathrm{La}$ "gracia o merced real" es una de las figuras jurídicas por medio de la cual la Corona castellana (o las autoridades facultadas para ello) concede a los particulares, en Hispanoamérica, el derecho al dominio privado de la tierra. La "moderada composición" es el mecanismo a través del cual la Corona busca regularizar la situación de aquellos ocupantes de tierras sin títulos suficientes que amparen la posesión, mediante el pago de una suma proporcionada al valor de la misma. Ver Ots Capdequi, 1945: 273-292.

11 La Ley de Enfiteusis del 1 de julio de 1822 acuerda la no enajenación de la tierra pública de la provincia de Buenos Aires a partir del traspaso, a los particulares, del derecho al usufructo sobre la misma por un lapso de veinte años (según la ley de 1826 que regula su funcionamiento) a cambio del pago de un canon. De esta manera, el Estado provincial entrega a manos de particulares un total de 6703430.4 ha, entre 1823 y 1840. En la zona ubicada al noroeste del río Salado se conceden 2.037.347,1 ha y en la noreste 450.098,1 ha hasta 1834, resultando Monte, Chascomús, Ranchos y Magdalena los sitios más requeridos. Al sur del mismo, por su parte, se entregan $4166208 \mathrm{Ha}$, hasta el año 1840, siendo Tandil, Monsalvo y Bahía Blanca las áreas de mayor demanda. Infesta, M. E., 1993: 93-120; Registro Oficial del Gobierno de Buenos Aires, 1821-1823: 117 .

12 A través de la Ley de Arrendamientos del 21 de octubre de 1857 (que se aplica durante catorce años), el Estado provincial ofrece en arrendamiento tierras públicas por el lapso de ocho años. Se establece que el 
llos cuyos derechos de usufructo habían comprado a algún particular. Esta oferta estatal de tierras coexiste en Dolores con otra privada que, por medio de la venta, la herencia, la cesión, la donación, la permuta, el "arreglo de cuentas", constituye otra modalidad de acceso a la tierra.

Los diversos caminos a los que hiciéramos mención arriba se refieren a las distintas etapas o escaiones de posible tránsito en el proceso de acceso a la tierra en la zona y período tratados. Entre ellos podemos referirnos a la ocupación de hecho de la tierra y la puesta en producción que se inicia ya a fines del siglo XVIII cuando algunos colonos se aventuran "más aliá" del Salado; a la denuncia de la misma; a la adquisición del derecho de posesión legal durante las décadas de 1820 y 1830 (enfiteusis) y la de 1850 (arrendamiento), precedida o no por ocupación de hecho; y a la apropiación legal, a lo largo de todo el período analizado, precedida o no por ocupación de hecho o por derecho. En medio de estas fases, que no necesariamente se siguen en idéntica forma en todos los casos, es factible advertir una serie de traspasos entre particulares, bien de la tierra, bien de los derechos de usufructo sobre la misma.

Veamos algunos ejemplos a fin de ilustrar lo antedicho.

Con relación a las tierras realengas o públicas que el Estado otorga a los particulares directamente en propiedad, entre las décadas de 1790 y 1830 , podemos señalar, que:

- En 1806 el Estado entrega 24.300 ha de tierras realengas situadas en el paraje conocido como "Los Dos Talas", en moderada composición, a Don Julián Martínez de Carmona, quien según testigos había ocupado y poblado el terreno siete u ocho años antes (hacia 1798-1799 aproximadamente) y lo había denunciado en 1804. Recordemos que Carmona figura entre aquellos pioneros que se aventuran, desde fines del siglo XVIII, hacia las tierras ubicadas al sur del río Salado.

- El 19 de agosto de 1807 se otorga, por "gracia del Superior Gobierno", un terreno cuyas dimensiones desconocemos, a Don Francisco Miguens.

- El 15 de abril de 1819 el Estado concede a Don Santos Calvento una merced de 32.400 ha solicitadas en 1817, en el paraje "La Quinua", a inmediaciones de Kakel $^{13}$.

- El 12 de enero de 1820 el Estado dona en propiedad, a Don José Ellauri, 43.200 ha ubicadas en el Paraje María Antonia (según decreto del 16 de mayo de 1817).

- El 31 de julio de 1821 (1830 según la mensura № 19 del Partido de Castelli) el Estado vende, a Don Juan Gregorio Almirón, 4.725 ha de tierras públicas en el pa-

precio a pagar por legua cuadrada $(2.700 \mathrm{ha})$ no excedería los $\$ 10.000$ ni bajaría de los $\$ 2.000$ para las tierras ubicadas dentro de la frontera. Las que están fuera de ella, por su parte, quedan exceptuadas de pago. La ley estipula, además, que no se pueden obtener más de tres leguas al interior del Salado o seis al exterior del mismo y fija los derechos de los subarrendatarios. Entre 1857 y 1873 se entregan en arrendamiento, en la provincia de Buenos Aires, un total de 4.076.792 ha. Valencia, $1986: 89-101$.

13 Dada la fecha de esta concesión (1819) creemos posible que la denominación "merced", que aparece en las fuentes, sea en el sentido de "gracia del gobierno". 
raje conocido como "Laguna la Vulada (?)", denunciadas por dicho Almirón tras una ocupación declarada de más de veinte años.

Otros, en cambio, acceden al derecho al usufructo de la tierra pública bajo las modalidades de la enfiteusis (décadas de 1820 y 1830) y/o el arrendamiento (década de 1850), habiendo ocupado o no el terreno con anterioridad. Ellos mismos o algún beneficiario de los derechos traspasados podían, ateniéndose a la legislación sobre el particular, adquirir finalmente las tierras en propiedad. Así, por ejemplo:

- El 18 de septiembre de 1826 Don Ramón Lara obtiene 10.044 ha en enfiteusis en las inmediaciones del Tordillo, cuyos derechos vende a Don Andrés Burgos el 29 de mayo de 1833 . Recién en agosto de 1838 y tras sucesivas ventas de estos derechos (Don Andrés Burgos a favor de su esposa Doña Saturnina Troncoso el 6 de mayo de 1838 y ésta a Don Juan Nonell el mismo año), Don Juan Nonell compra el terreno al Estado.

- El 25 de octubre de 1826 Don Juan Madrid obtiene en enfiteusis un terreno público de 5.400 ha ubicado en el Rincón de Ajó, que ocupaba desde 1818 y había solicitado el 8 de junio de 1826. El 4 de septiembre de 1838 su hijo Don Juan Madrid, tras haber obtenido nuevamente el campo en enfiteusis el 11 de marzo de 1833, lo compra al Estado.

- El 13 de abril de 1859 Don Juan Mariano Pereyra obtiene 5.400 ha de tierra pública en arrendamiento, que ya ocupaba y había solicitado el 10 de febrero del mismo año. Finalmente, las compra al Estado el 7 de junio de 1869.

- En fecha sin precisar, Don Crisóstomo Vega obtiene de su madre los derechos de arrendamiento al terreno de 2.700 ha, situado en "la costa" de los Montes del Tordillo, que bajo este concepto fue entregado el 29 de noviembre de 1858 a Don José María Zapiola y que ésta adquirió. En 1866 Doña Inocencia Cepeda de Maydana, subarrendataria de dicho Vega, compra al Estado la fracción que subarrien$\underline{\text { da, }}$ compuesta de 675 ha.

Otra modalidad de acceso a la propiedad de la tierra es adquiriéndola, bajo diferentes formas (venta, herencia, cesión, donación, permuta, obtención por "arreglo de cuentas"), de un particular que ya la posee en propiedad. Así:

- El 6 de mayo de 1830 Don Gervasio Rosas adquiere 22.275 ha en propiedad en la estancia del "Rincón", por arreglo de cuentas con Don Braulio Costa.

- El 2 de enero de 1830 Don Justo Piñero obtiene en propiedad 2.700 ha en el paraje denominado "Marica", que le son permutadas por Don José Echenagusía.

- El 23 de junio de 1837 Don Hipólito Piñero vende a Don Ambrosio Crámer 4.050 ha de su propiedad, situadas en el Paraje denominado "Los Rengos".

- En 1847 Don Juan Madrid cede a su hermano Don Félix Madrid, por convenio particular entre ambos, 2.700 ha de terreno de su propiedad en el Rincón de Ajó. Con anterioridad a 1853, en fecha sin precisar, Don Francisco Olarriaga obtiene de su padre (cuyo nombre desconocemos) 337,5 ha en propiedad, bajo la forma 
de donación.

- Hacia 1855 Don Marcos, Doña Justa, Doña Francisca y Don Lázaro Tapia obtienen $1.518,7$ ha en propiedad cada uno en concepto de herencia, tras la muerte de su padre Don Santiago Tapia.

Tal como ilustran los ejemplos mencionados, es posible advertir una complementariedad en las formas de acceso al usufructo y a la propiedad legal de la tierra en la zona que nos ocupa. Si cotejamos esta información con la que nos brindan algunos trabajos recientes que abordan la problemática del acceso y la transferencia de la tierra para otras áreas de la campaña bonaerense, tanto en el período colonial como durante parte del siglo XIX, notamos algunas características comunes y otras distintivas.

Entre fines del período colonial y principios del siglo XIX, en la zona fronteriza comprendida por los actuales partidos de Chascomús, Monte y General Paz, las formas de acceder legalmente a la tierra realenga y/o pública son similares a las halladas en Dolores: algunas mercedes y compras directas al Estado, moderada composición, donaciones y tierras obtenidas en enfiteusis. Distinta es la situación en la zona del Arroyo Azul, al sur del río Salado. Aquí, las donaciones condicionadas por parte del Estado se dan de manera sistemática hacia principios de la década de 1830 inaugurando, así, una especie de "modelo colonizador" instaurado por el gobierno rosista también en otras áreas: Chacarita, San Andrés de Giles, San Miguel del Monte, Luján ${ }^{14}$. El hecho de ser ésta una zona central en la relación entre la sociedad "blanca" y la indígena habría llevado al Estado a implementar una política colonizadora de estas características. Si dirigimos ahora nuestra mirada a un área de temprana colonización como el partido de San Nicolás de los Arroyos vemos que, en fechas tan tempranas como los siglos XVII y XVIII, el pasaje de tierras realengas a manos privadas se opera a través de la adjudicación de tres mercedes reales. Estos estudios (a excepción del caso de Azul) presentan a la venta y a la herencia como las modalidades predominantes de traspaso de tierras entre los particulares en los partidos fronterizos y, sumadas a éstas, la donación, la adjudicación y la dote en el de San Nicolás's.

Destaquemos, asimismo, la cuestión de los "pobladores" a la que nos remite la mención de la ocupación de hecho de la tierra. De igual modo que lo hallado al estudiar los procesos colonizadores de otras zonas de la campaña bonaerense (entre ellas San Nicolás de los Arroyos, Areco, Arrecifes, Luján, Magdalena, Lobos, Chascomús), en Dolores también encontramos a estos productores que, muchas veces junto a sus familias, se asientan en tierras baldías o al menos sin dueño conocido ya desde fines del siglo XVIII. Mientras algunos acceden en algún momento al derecho legal al usufructo de la tierra o, por qué no, a la propiedad de la mis-

14 Estas "donaciones condicionadas" efectuadas por el gobierno de Juan Manuel de Rosas implican la obligación, por parte del agraciado, de población y defensa de la frontera. Infesta y Valencia, 1987: 177-211. 15 Banzato, 1998: 37-64; Canedo, 2000; Lanteri, 2000 (mimeo). 
ma, otros nunca lo logran. Así, o son desalojados de los campos que ocupan o consiguen permanecer en los mismos en calidad de "tolerados"16.

Por último, es de remarcar la presencia del arrendamiento de tierras públicas al Estado en Dolores, según la mencionada ley de 1857. Si bien ésta estipula entregar tierras bajo ese concepto tanto al interior como al exterior de la frontera, un estudio de Marta Valencia señala que es en los partidos fronterizos donde se localiza el mayor porcentaje de arrendamientos ${ }^{17}$.

\section{La tierra, del Estado a los particulares}

La superficie de terreno adjudicada por el Estado a los particulares, bajo diferentes modalidades, es de $592.090,6$ ha hacia 1840 y de $634.020,8$ ha hacia $1860^{18}$. Aclaremos que parte de la superficie de la zona es de propiedad pública y figura como baldía. La misma no ha podido ser calculada, salvo un sobrante de $1.496,1$ ha. Dentro del área en estudio se suman, a su vez, 10.800 ha que corresponden al pueblo de Dolores, las quintas y las chacras ${ }^{19}$ y 24.310 ha que ocupan los Montes del Tordillow.

Ahora bien, ¿ de qué manera y en qué cantidades el Estado va traspasando entre 1798 y 1860 , a los particulares, las tierras primero realengas, más tarde públicas? Ya expusimos que entre los mecanismos de traspaso se encuentran el de adjudicar la tierra directamente en propiedad a través de venta, concesiones de merced y por "gracia del gobierno", moderada composición y donación (entre la década de 1790 y mediados de la de 1820), y el de otorgar el derecho al usufructo de la misma bajo las formas de la enfiteusis (décadas de 1820 y 1830) y del arrendamiento (década de 1850).

A través de 57 traspasos el Estado adjudica a los particulares 658.149 ha, entre 1798 y $1860^{21}$. Un volumen de $343.169,9$ ha $(52,1 \%$ del total de las mismas)

16 La presencia de "pobladores" en el partido de Dolores queda en evidencia tanto a partir de la mención a los mismos en la documentación consultada como de su presencia en los planos que los agrimensores realizan del terreno objeto de mensura. Debido a que por cuestiones de espacio no nos podemos explayar aquí sobre esta problemática remitimos al lector a Mascioli, 1999: 64-98 (mimeo).

17 Si bien Marta Valencia, en su estudio sobre los arrendamientos de tierras públicas en la provincia de Buenos Aires entre 1857 y 1872 , no menciona el partido de Dolores, nombra los de Pila y Vecino (actual General Guido) que, como vimos, son parte del de Dolores antes de 1839. Valencia, M., 1986: 89-101. El arriendo en la campaña bonaerense no es un fenómeno nuevo de mediados del siglo XIX sino una práctica que, con características diferentes, ya existe con anterioridad. Fradkin, 1991 (mimeo); 1993: 40-69; 1995: 39-64.

18 La diferencia entre las superficies de ambas fechas se debe no sólo a la adjudicación a los particulares, hacia 1860 , de tierras que en 1840 son de propiedad pública y declaradas baldías, sino también a los reajustes que se van operando sobre el área de los terrenos (por lo general un incremento de la misma), a medida que éstos van siendo mensurados. Con relación a la superficie dada para 1860, cabe aclarar que $3.777,4$ ha corresponden a tierras del Estado que se hallan dentro de los terrenos de dos propietarios.

19 Roncoroni, 1967: 28-48.

20 Duplicados de Mensuras del Partido de Dolores, $N^{\circ} 48$ (año 1881), AHGyC. des, entre 1798 y $1860,46.715,4$ ha corresponden a terrenos que son cedidos dos veces: entre las décadas 
es otorgado en propiedad en 16 traspasos ( $28 \%$ de los mismos), mayormente a través del mecanismo de la venta; $262.312,1$ ha (39,9\% del total de las mismas) lo es mediante 22 traspasos (38,5\% de los mismos) bajo la forma de la enfiteusis y, por último, 52.667 ha ( $8 \%$ de la tierra adjudicada) es entregada bajo la modalidad del arrendamiento, en un total de 19 traspasos (33,5\% de los mismos) (Ver gráfico 1 y planos 1,2 y 3 ).

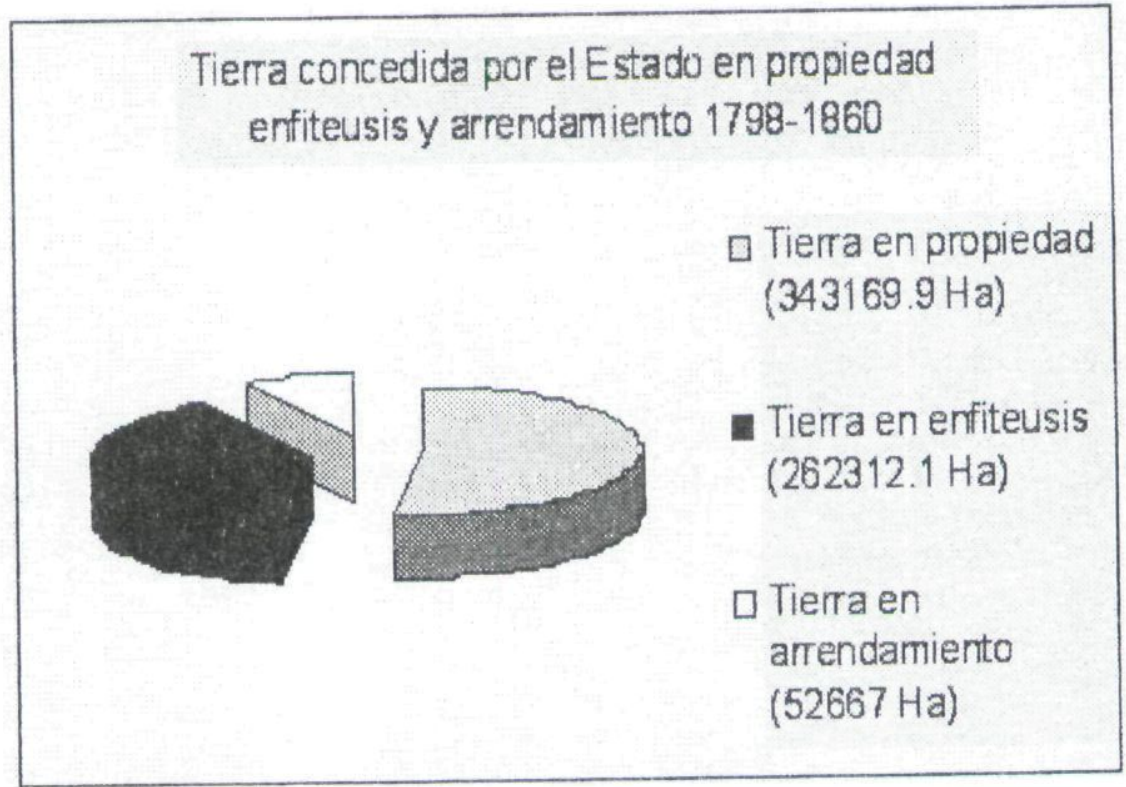

Fuentes. Mensuras Antiguas al sur del Salado. Duplicados de mensuras del Partido de Doiores, Castelli, Pila, Tordillo, General Guido y General Lavalle, Libro de enfiteusis 1825-1840. Registro de arrendamientos y enfiteusis-ventas 1818-1838 (AHGyC). Legajos Sección Escribania Mayor de Gobierno (AHPBA).

de 1820 y 1830 son otorgados en enfiteusis a Doña Tadea Morales (?), Don Crisóstomo Arroyo, Don Mariano Ramírez, Don Manuel Rico, Don Damasio Vallejos, Doña María Ignacia Lara, Doña Simona Palomeque, Don José María Montañéz y Doña Paula Medina y, en la de 1850, son nuevamente adjudicados bajo la forma del arrendamiento a Don Manuel María Díaz, Doña Dolores Alegre (o Agrelo?), Don Mariano Mendiburu, Don Fermín White, Don Daniel Hibarguengoitia, Doña Catalina Revol de Morete, Don Manuel Ramírez, Don Marcelino Salvatierra, Don Manuel Vallejos, Don Pedro Juárez, Doña Simona Palomeque, Don Guillermo White, Don Mariano Nadal, Don José María Zapiola y Don Juan Botet; 32.400 ha corresponden a un campo adjudicado primero en merced a Don Lorenzo López, hacia 1821, y posteriormente en enfiteusis a los herederos de Don Pedro Alcántara Capdevila, en 1829; 5.400 ha son de un terreno otorgado dos veces en enfiteusis: a Don Francisco Madrid en 1826 y a su hijo Don Juan Madrid en 1833 ; y 16.200 ha corresponden a un campo cuyos derechos cede un particular a Don Juan Miguens, que las obtiene nuevamente en merced, en 1819. 
PLANO 1 - Dolores, 1830.

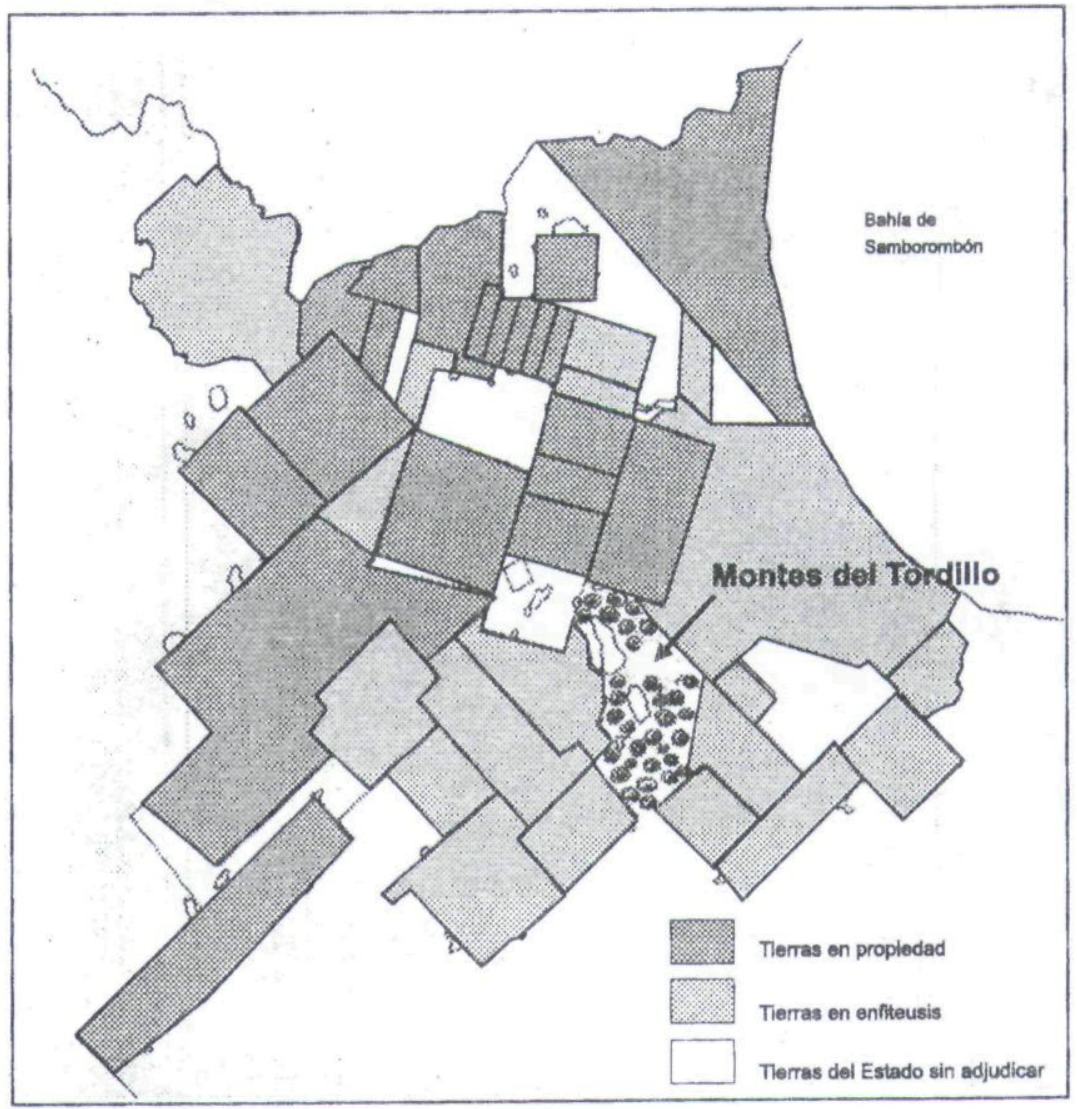

NOTA: Agunos terrenos, de los que poseemos informacion que fue analizada, no pudieron ser ubicados en el plano. Tempoco pudieron serto los sobrantes públicos que se hallen dentro de los campos. Para más detalle ver los cuadros de sistematización de ios datos en alApéndice Generall.

Fuente: Elaboración propia en base a Duplicados de Mensuras de los partidos de Dolores, Castelii, Tordilio, Plia, Gral. Lavalle y Gral. Guido; Mensuras Antiguas al sur dei Salado; Registro Gráfico de la Provincia de Buenos Ares de 1864 (AHGyC); Legajos varios de la sección Escribania Mayor de Goblemo (AHPBA). 
PLANO 2 - Dolores, 1840.

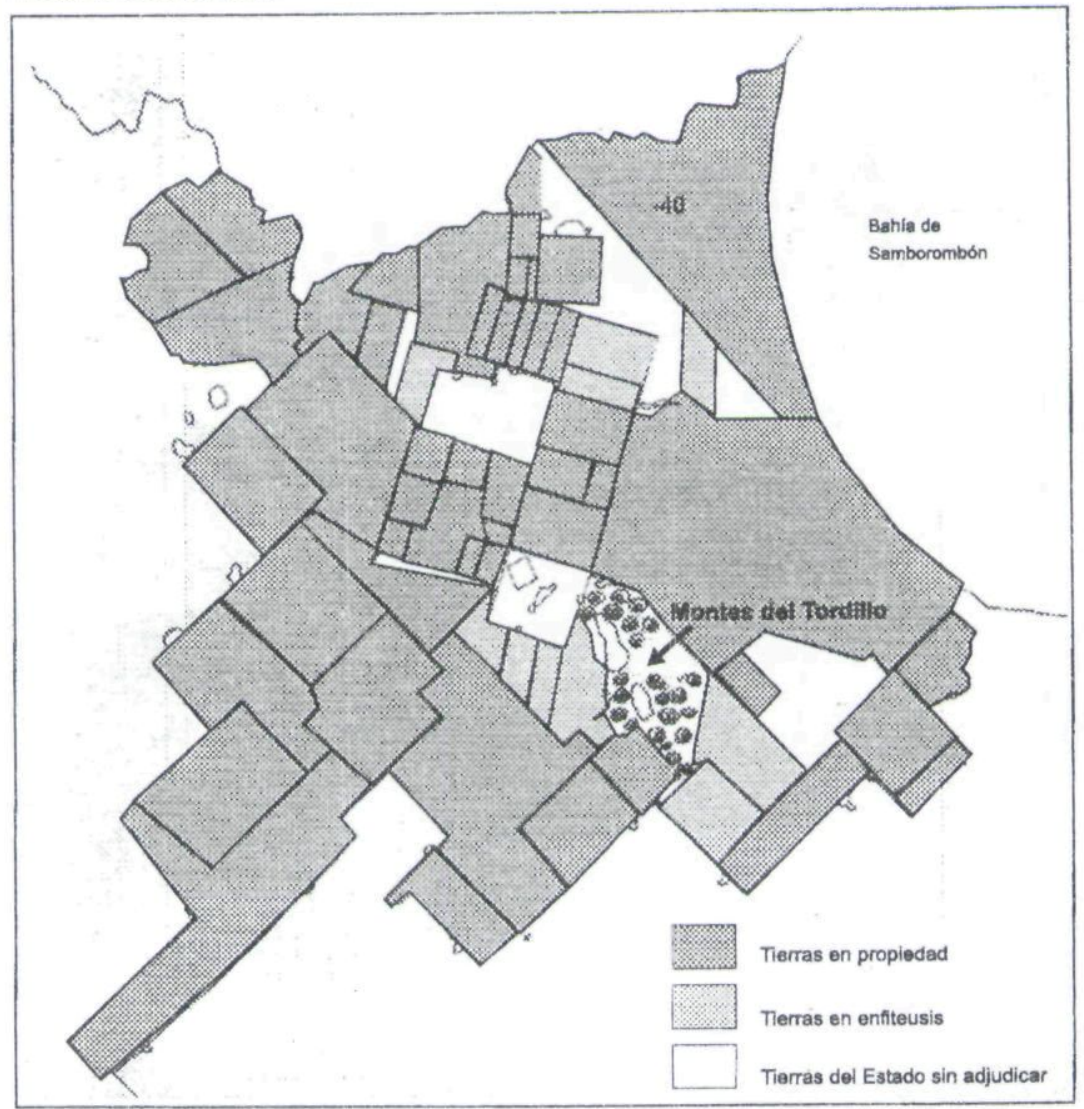

NOTA: " Algunos terrenos, de los que poseemos información que fue analizada, no pudieron ser ubicados en el plano. Tampoco pudieron serio los sobrantes públicos que se hallan dentro de los campos. Para más detalle ver los cuadros de sistematización de los datos en el Apéndice Generail.

- $(-40)$ : La información que poseemos no llega hasta 1840

Fuente: Elaboración propia en base a Duplicados de Mensuras de los partidos de Dolores, Castelli, Tordillo, Pila, Gral. Lavalle y Gral. Guido; Mensuras Antiguas al sur del Salado; Registro Gráfico de la Provincia de Buenos Aires de 1864 (AHGyC); Legajos varios de la sección Escribania Mayor de Gobierno (AHPBA). 
PLANO 3 - Dolores, 1860.

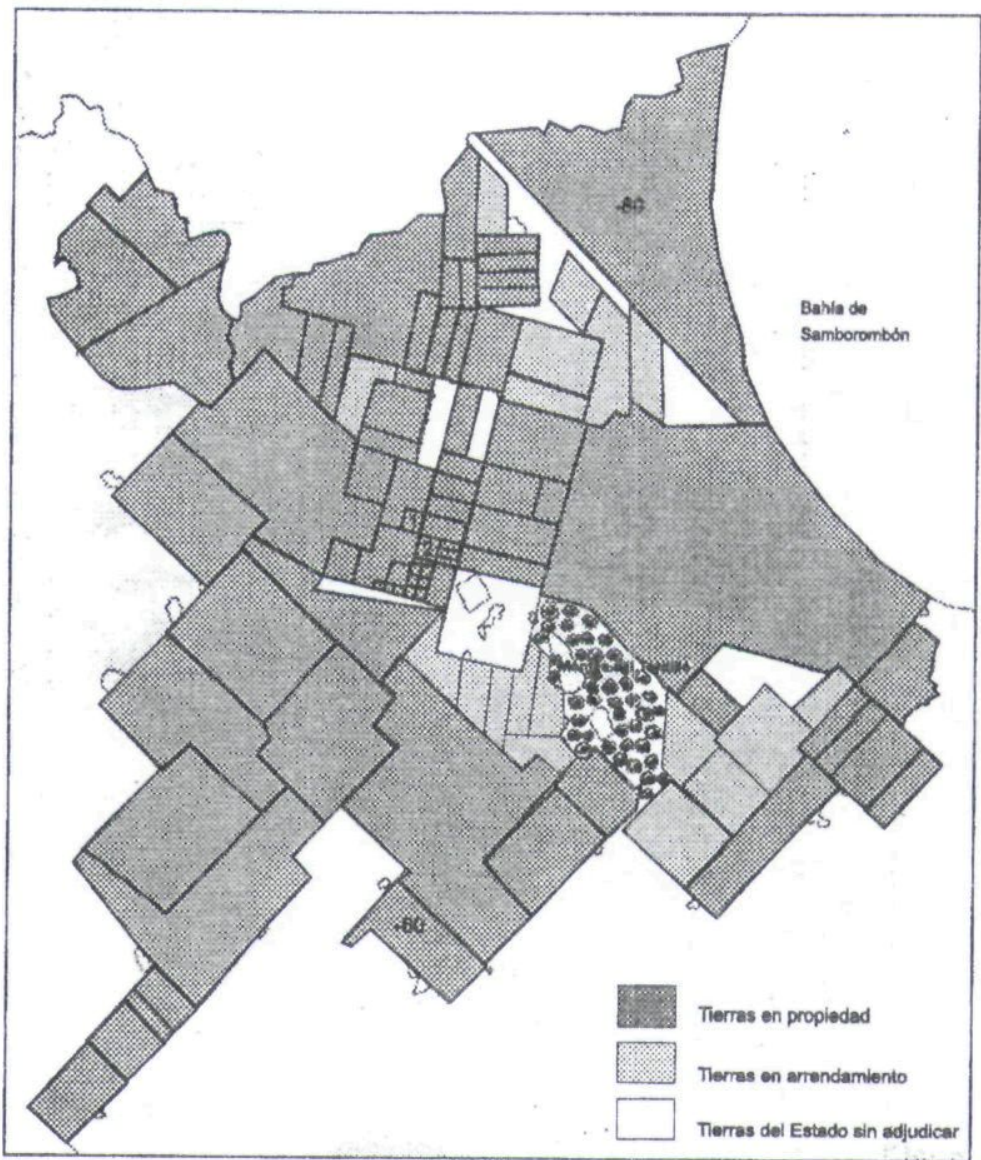

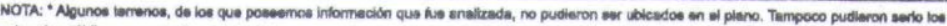

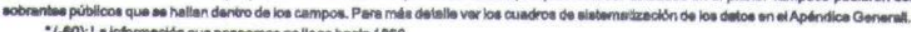

- (-60): La información que poecernoe no llega haula 1860

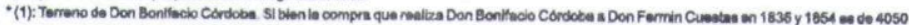

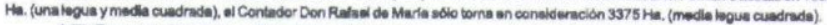



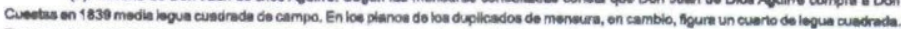
Tanto en el caso 1 como en el 2 se conaiderb media legue ousobrada al analizar la información.

Fuente: Elaboración propia en base a Duplicados de Mensuras de los partidos de Dolores, Castelii, Tordillo, Pilla, Gral. Lavalle y Grai. Guido; Mensuras Antiguas ai sur del Salado; Registro Grafico de la Provincia de Buenos Aires de 1864 (AHGyC); Legajos varios de la sección Escribanla Mayor de Gobiemo (AHPBA). 
La relación que existe entre el número total de traspasos y el volumen de tierra otorgada bajo las diferentes formas enunciadas nos sugiere que, según sea la modalidad de acceso a la tierra y a medida que el proceso colonizador de la zona avanza las superficies otorgadas son, en promedio, cada vez menores. Así, los mayores terrenos habrían sido los adjudicados en propiedad (promedio de 21.448 ha cada uno), seguidos de aquellos dados en enfiteusis (promedio de 11.923 ha cada uno) y, por último, en arrendamiento (promedio de 2.771 ha cada uno).

El mayor número de traspasos de tierras del Estado a los particulares se concentra en las décadas de 1820 y 1850 a partir, fundamentalmente, de las concesiones en enfiteusis y arrendamiento respectivamente $(63,4 \%$ del total de los traspasos del período estudiado). Si nos atenemos al volumen de hectáreas otorgadas, en cambio, es la década de 1820 la que registra la mayor cantidad de tierra concedida (40,5\% del total de la misma) y es la adjudicación en enfiteusis la que prevalece.

Un elemento que llama la atención es la ausencia de operaciones en la década de 1840. Esta particularidad es también observada por María Elena Infesta en su trabajo sobre las concesiones enfitéuticas en Buenos Aires, entre 1820 y 1850 . Si bien podríamos pensar que esta "inactividad" no es tal, sino sólo producto de que no han llegado hasta nosotros registros legales o formales de transferencias de tierras públicas hacia los particulares, María Elena Infesta relaciona el fenómeno con la situación del momento. Así, afirma que los conflictos tanto internos como externos que acaecen en esa "década revuelta" serían los causantes de esta "desaceleración" en el proceso de adjudicación de tierras públicas ${ }^{22}$.

\section{Transferencias entre particulares}

Como señaláramos, entre los varios caminos que permiten a los individuos acceder tanto al usufructo como a la propiedad de la tierra en la zona que nos ocupa entre 1798 y 1860 , se halla el de obtenerla de un particular bajo la forma de la venta, la herencia, la cesión, la permuta, la donación, el "arreglo de cuentas" y otras en las que no se especifica la modalidad. Según indicamos se transfieren entre particulares tanto tierras privadas como derechos de usufructo sobre las públicas (aquellas concedidas en enfiteusis y arrendamiento $)^{23}$ (Ver cuadros 1 y 2 ).

22 Infesta, 1993: 93-120. En su estudio sobre el proceso colonizador en San Nicolás de Los Arroyos, Mariana Canedo observa un fenómeno de "desaceleración" semejante, en la década de 1840, en lo concerniente a las transferencias de tierras entre particulares. Ello nos estaría indicando, por lo tanto, que se trataría de algo más que de un problema de registro (Canedo, 2000).

23 María Elena Infesta plantea la existencia de traspasos entre particulares de derechos sobre tierras concedidas en enfiteusis en el territorio bonaerense, entre 1826 y 1839 . En la zona objeto de nuestro estudio, sin embargo, es posible advertirlos al menos hasta fines de la década de 1850 (Infesta, 1993 :93-120). En el período de tiempo aquí considerado, por su parte, no se registran traspasos entre particulares de derechos sobre tierras concedidas en arrendamiento. 


\section{CUADRO 1. TRASPASOS, ENTRE PARTICULARES, DE LOS DERECHOS SOBRE TIERRAS PUBLICAS (CONCEDIDAS EN ENFTTEUSIS) Y TIERRAS EN PROPIEDAD, 1798-1860.}

\begin{tabular}{|l|c|c|c|c|c|c|l|l|l|l|}
\hline Forma & Venta $\mathrm{N}^{\circ}$ & $\%$ & Herencia $\mathrm{N}^{\circ}$ & $\%$ & $\begin{array}{l}\text { Otros } \\
\mathrm{N}^{*}\end{array}$ & $\%$ & $\begin{array}{l}\mathrm{S} / \mathrm{E} \\
\mathrm{N}^{\circ}\end{array}$ & $\begin{array}{l}\text { Total } \\
\mathrm{N}^{\circ}\end{array}$ & $\%$ \\
\hline 1790 & $\ldots$ & -- & $\ldots$ & $\ldots$ & $\ldots$ & $\ldots$ & $\ldots$ & $\ldots$ & $\ldots$ & $\ldots$ \\
\hline 1800 & $\ldots$ & -- & 2 & 3.7 & $\ldots$ & $\ldots$ & 1 & 20 & 3 & 1.6 \\
\hline 1810 & 2 & 1.8 & - & - & $\ldots$ & $\ldots$ & $\ldots$ & $\ldots$ & 2 & 1.1 \\
\hline 1820 & 22 & 20 & 3 & 5.6 & $3(1)$ & 30 & $\ldots$ & $\ldots$ & 28 & 15.8 \\
\hline 1830 & 41 & 37.4 & 9 & 17 & $3(2)$ & 30 & 1 & 20 & 54 & 30.4 \\
\hline 1840 & 7 & 6.3 & 5 & 9.4 & $1(3)$ & 10 & $\ldots$ & $\ldots$ & 13 & 7.3 \\
\hline 1850 & 33 & 30 & 10 & 18.9 & $1(4)$ & 10 & $\ldots$ & $\ldots$ & 44 & 24.7 \\
\hline S/F & 5 & 4.5 & 24 & 45.4 & $2(5)$ & 20 & 3 & 60 & 34 & 19.1 \\
\hline Total & 110 & 100 & 53 & 100 & 10 & 100 & 5 & 100 & 178 & 100 \\
\hline & 110 & 61.9 & 53 & 29.7 & 10 & 5.6 & 5 & 2.8 & 178 & 100 \\
\hline
\end{tabular}

\section{Propiedad pública.}

Terrenos traspasados por venta, cuyas superficies no están especificadas: 1 en 1820,1 en 1830 y 1 en 1840.

Los traspasos por herencia, cuyas fechas no están consignadas, creemos que se ubicarían entre las décadas de 1820 y 1830.

(1) Comprende 46.251 ha cedidas.

Nota. Los traspasos por venta y cesión son todos entre particulares, excepto una venta entre familiares en la década de 1830.

\section{Propiedad privada.}

Terrenos traspasados por venta, cuyas superficies no están especificadas: 1 en 1810, 1 en 1820, 2 en 1830, 3 en 1850 y 2 sin fecha consignada.

Terrenos traspasados por herencia, cuyas superficies no están especificadas: 1 en 1850, 1 en 1860 y 5 sin fecha consignada.

(2) Incluye 229,5 ha cedidas, 22.275 ha traspasadas por "arreglo de cuentas" y 2.700 ha. permutadas.
(3) Comprende 2.700 ha cedidas.

(4) Comprende 632,8 ha donadas.

(5) Comprende 337,5 ha donadas y 540 ha cedidas. Nota. Todos los traspasos (exceptuados los de herencia) son entre particulares, salvo tres ventas entre familiares (una en la década de 1840 y dos en la de 1850 ), dos donaciones entre familiares (una en la década de 1850 y la otra sin fecha), una cesión entre familiares ( $\sin$ fecha), un traspaso sin espe cificar de qué tipo, entre familiares (sin fecha) y tres traspa. sos sin indicar entre quiénes (uno en la década de 1800, otro en la de 1830 y uno sin fecha).

Referencias. S/F: $\sin$ fecha

S/E: Sin especificar la modalidad de traspaso. Fuentes. Mensuras Antiguas al sur del Salado. Duplicados de mensuras del Partido de Dolores, Castelli, Pila, Tordillo, General Guido y General Lavalle. Libro de enfiteusis 1825 . 1840. Registro de arrendamientos y enfiteusis-ventas 1818 1838 (AHGyC). Legajos Sección Escribanía Mayor de Gobierno (AHPBA).

Como podemos observar, la transferencia de tierras entre particulares en el período abordado, que cobra auge a partir de la década de 1820 , involucra un volumen de $1.417 .707,4$ ha y un total de 178 traspasos, bajo las formas de la venta y de la herencia predominantemente $(61,9 \%$ de los traspasos y $53,7 \%$ del total de hectáreas involucradas para la primera y $29,7 \%$ de los traspasos y $37,9 \%$ del volumen total de hectáreas transferidas para la segunda ${ }^{24}$.

24 Mariana Canedo también observa, en el caso de San Nicolás de Los Arroyos, el notable impulso que cobran las transferencias de tierras entre particulares a partir de 1820. Ello se vincularía al aumento del precio de los productos pecuarios y de la tasa de utilidad del ganado vacuno que derivaría, a su vez, en una peculiar relación con el mercado internacional. Así la tierra, cuyo precio comienza a incrementarse hacia 1819-1820, sería una posibilidad de inversión para aquellos que quieren proteger sus intereses. Canedo, 2000; Garavaglia, 1995: 65-112; 1999 (mimeo). Alejandra Irigoin, por su parte, explica la inversión en tierras y ganados en la década de 1820 como un mecanismo tendiente a proteger los capitales líquidos frente a la inseguridad de los mismos en un contexto de inflación monetaria. Irigoin, 2000 (mimeo). 
CUADRO 2. TRASPASOS, ENTRE PARTICULARES, DE LOS DERECHOS SOBRE TIERRAS PUBLICAS (CONCEDIDAS EN ENFTIEUSIS) Y TIERRAS EN PROPIEDAD, 1798-1860.

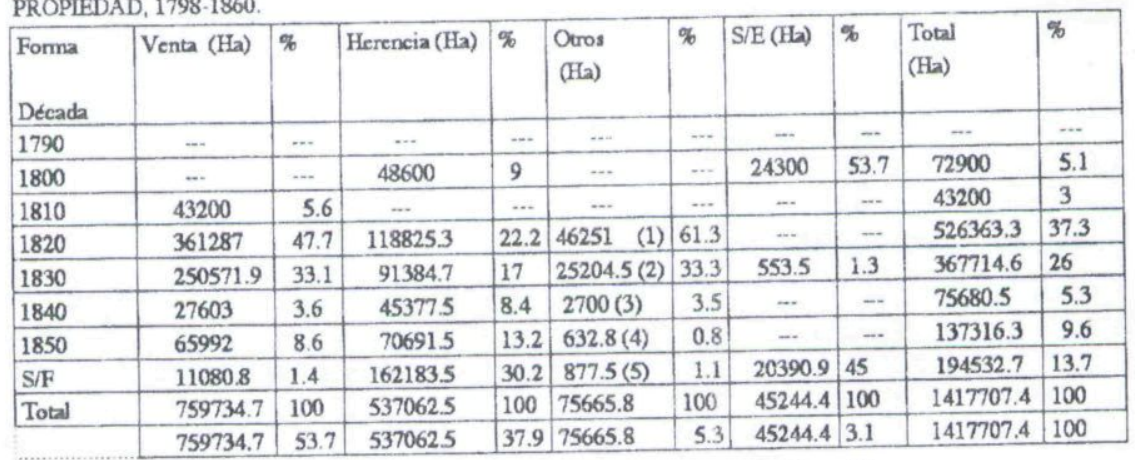

Propiedad pública.

Terrenos traspasados por venta, cuyas superficies no están especificadas: 1 en 1820,1 en 1830 y 1 en 1840.

Los traspasos por herencia, cuyas fechas no están consignadas, creemos que se ubicarian entre las décadas de 1820 y 1830.

(1) Comprende 46.251 ha cedidas.

Nota. Los traspasos por venta y cesión son todos entre particulares, excepto una venta entre familiares en la década de 1830.

Propiedad privada.

Terrenos traspasados por venta, cuyas superficies no están especificadas: 1 en 1810, 1 en 1820, 2 en 1830, 3 en 1850 y 2 in fecha consignada.

Terrenos traspasados por herencia, cuyas superficies no están especificadas: 1 en 1850, 1 en 1860 y 5 sin fecha consignada.

(2) Incluye 229,5 ha cedidas, 22.275 ha traspasadas por "arreglo de cuentas" y 2.700 ha permutadas.
(3) Comprende 2.700 ha cedidas.

(4) Comprende 632,8 ha donadas.

(5) Comprende 337,5 ha donadas y 540 ha cedidas.

Nota. Todos los traspasos (exceptuados los de herencia) son entre particulares, salvo tres ventas entre familiares (una en la década de 1840 y dos en la de 1850), dos donaciones entre familiares (una en la década de 1850 y la otra sin fecha), una cesión entre familiares (sin fecha), un traspaso sin especificar de qué tipo, entre familiares (sin fecha) y tres traspasos sin indicar entre quiénes (uno en la década de 1800, otro en la de 1830 y uno sin fecha).

Referencias. $5 / F$ : sin fecha

S/E: Sin especificar la modalidad de traspaso. Fuentes. Mensuras Antiguas al sur del Salado. Duplicados de mensuras del Partido de Dolores, Castelli, Pila, Tordillo, General Guido y Ceneral Lavalle. Libro de enfiteusis 1825 1840. Registro de arrendamientos y enfiteusis-ventas 1818 1838 (AHCyC). Legajos Sección Escribanía Mayor de Cobierno (AHPBA).

Si analizamos estas transferencias por década y por modalidad vemos que en número de traspasos se destacan las décadas de 1830, 1850 y 1820 (en ese orden) con el $30,4 \%, 24,7 \%$ y $15,8 \%$ del total de los mismos respectivamente. Con relación al volumen de tierra involucrada, en cambio, el orden se invierte pasando a ocupar el primer lugar la década de 1820 (37,3\% del total de hectáreas traspasadas), seguida por la de 1830 ( $26 \%$ del volumen total de tierra transferida). Siguiendo la tendencia general mencionada, la venta constituye la modalidad de traspaso predominante en estas décadas, ya que involucra el $76,1 \%$ del total de traspasos operados en las décadas de 1820,1830 y 1850 y el $68,4 \%$ de hectáreas traspasadas entre particulares en los decenios de 1820 y $1830^{25}$.

La relación entre la cantidad de traspasos y de hectáreas involucradas nos sugiere que, en promedio, las mayores superficies se habrían transferido entre par-

25 Cabe aclarar que el $19,1 \%$ de los traspasos entre particulares tanto de tierras privadas como de los derechos sobre las públicas (34) y el 13,7\% de las hectáreas transferidas (194.532,7 ha) no han podido ser fechados. En ambos casos predomina el traspaso por herencia. 
ticulares en la década de 1820 (promedio de $187.98,6$ ha), seguida por las de 1830 (promedio de $6.809,5 \mathrm{ha}$ ) y 1850 (promedio de $3.120,8 \mathrm{ha}$ ). Nótese, al igual que en lo concerniente al traspaso de tierras del Estado a los particulares, la merma de transferencias en la década de 1840 respecto a los decenios inmediatos anteriores y posteriores.

Las transferencias entre particulares de los derechos sobre tierras concedidas en enfiteusis, que como ya advertimos llegan al menos hasta 1859 , involucran un total de 322.780 ha en 40 traspasos. Las tierras en propiedad transferidas entre particulares a través de 138 traspasos, por su parte, suponen un total de 1.094.927,4 ha.

Con relación a las transferencias de los derechos sobre tierras públicas, operados mayormente a través del mecanismo de la venta, las décadas de 1830 y 1820 son, en ese orden, las que registran tanto el mayor número de traspasos $(50 \%$ y $25 \%$ del total de los mismos respectivamente) como de cantidad de hectáreas involucradas $(50,3 \%$ y $31,5 \%$ del total de hectáreas traspasadas respectivamente). Siguiendo la tendencia general ya apuntada la venta, seguida de la herencia, constituye la modalidad predominante en estas transferencias, tanto si tomamos en consideración el número de traspasos como el volumen de hectáreas ${ }^{26}$.

Respecto a las transferencias entre particulares de las tierras en propiedad, donde también predomina la venta como modalidad, vemos que es en las décadas de 1850 y 1830 , en ese orden, cuando se da el mayor número de traspasos $(29,8 \%$ y $24,8 \%$ del total de los mismos respectivamente) y en la de 1820 donde se registra el mayor volumen de hectáreas traspasadas ( $39 \%$ del total de las mismas). La venta sigue siendo, en cada uno de estos decenios, la forma de traspaso que prima ${ }^{27}$.

Según vimos, lo que se traspasa entre los individuos es tanto el dominio privado sobre la tierra como los derechos al usufructo de la misma. No obstante, en ciertas oportunidades, entran también en la operación instalaciones, animales, herramientas, armas, utensilios, entre otros. Es posible, asimismo, encontrar que algunos de estos traspasos se hacen de manera extrajudicial.

\section{Del derecho al usufructo al dominio privado de la tierra}

Como expusimos al inicio de este trabajo, los poseedores de derechos enfitéuticos y de arrendamiento sobre las tierras podían, a partir de la promulgación de varias leyes al respecto, obtener la propiedad de las mismas mediante la compra al Estado ${ }^{28}$.

26 Vale aclarar que un 12,5\% del total de los traspasos de derechos sobre tierras en enfiteusis (5) y un 14,6\% de las hectáreas transferidas $(47.061 \mathrm{ha})$, no se han podido fechar. En estos casos, la herencia es la forma de traspaso predominante. 27 En el caso de los traspasos entre particulares de tierras en propiedad, el $21 \%$ de los mismos (29) y el $13,4 \%$ del total de hectáreas transferidas (147.471,7 ha) no poseen fecha consignada. La herencia es la modalidad de traspaso que prevalece. 
En la zona y período que nos ocupan, las tierras concedidas en enfiteusis pasan a dominio privado en la década de 1830 a través de 19 traspasos. Esta transferencia involucra un total de $213.818,4$ ha que representan el $81,5 \%$ del total de tierras que fueran otorgadas en enfiteusis en las décadas de 1820 y 1830 . De las $48.493,7$ ha restantes, que no son vendidas a los particulares, pudimos calcular que al menos $467.15,4$ ha son concedidas nuevamente bajo la modalidad del arrendamiento a partir de $1857^{29}$.

Si relacionamos el total de hectáreas en enfiteusis traspasadas al dominio privado con el número total de traspasos, vemos que las superficies vendidas a los particulares tienen, en promedio, $11.253,6$ ha. Esta cifra está muy cercana a las 11.923 ha que habrían tenido, también en promedio, esas mismas tierras cuando fueron adjudicadas en enfiteusis.

$\mathrm{El}$ análisis precedente sobre las transferencias de tierras entre particulares y sobre la adjudicación en propiedad de aquellos terrenos que habían sido concedidos en enfiteusis, abre una serie de interrogantes entre los que se halla la cuestión de la estructura de tenencia de la tierra en la zona y período abordados.

\section{¿Concentración o parcelación de la tierra?}

Parte de la producción historiográfica que trata sobre la apropiación de la tierra en el territorio bonaerense, durante la primera mitad del siglo XIX, plantea que tanto las concesiones de terrenos públicos bajo las formas de la enfiteusis y del arrendamiento como las donaciones condicionadas e incondicionadas que tienen lugar durante el gobierno de Juan Manuel de Rosas, lejos de propiciar el poblamiento y la puesta en producción de la campaña habrían favorecido la especulación y, con ella, el acaparamiento de tierras $^{30}$.

Más recientemente algunos trabajos de María Elena Infesta y Marta Valencia cuestionan estas hipótesis aduciendo que los mencionados autores que se refieren al tema tratan sólo las cuestiones legales, no basando sus análisis en un "riguroso análisis de las fuentes disponibles". A su vez la principal confusión resulta, según las autoras y en el caso de las tierras concedidas en enfiteusis y arrendamiento, de considerar tanto las denuncias sin resolución como las sucesivas adiciones producto de las transferencias de las tierras públicas entre los particulares y, en el caso de premios otorgados por combates contra los indios y a la fidelidad, de no diferenciar

parte, salen a la venta en los años 1864, 1867 y 1871 (Valencia, 1986 :89-101 y Registro Oficial del Gobierno de Buenos Aires, 1864 :97-98). Las ventas a particulares de las tierras concedidas en arrendamiento, al escapar a los marcos temporales del presente estudio, no serán analizadas de manera sistemática.

29 Algunos autores han señalado las ventajas que habrían reportado, para aquellos que compran tierras concedidas en enfiteusis, los precios, medios y formas de pago. Ver Irigoin, 2000 (mimeo); Garavaglia, 2000 (mimeo). Con relación a la concesión en arrendamiento de tierras poseídas previamente en enfiteusis, ver nota 21 .

30 Pueden consultarse, entre otros, Coni, 1927; Avellaneda, 1865; Oddone, 1967; Cárcano, 1972; Carretero, 1972. 
entre certificados emitidos, retirados y efectivamente escriturados. El planteo que ellas proponen es, no obstante, que hay en el territorio bonaerense cierto aumento promedio de las superficies concedidas tanto en enfiteusis (en 1836 respecto a 1827) como en arrendamiento ya que la acumulación se habría producido por la vía de las transferencias entre particulares ${ }^{31}$.

Con relación a la zona norte del río Salado, Hilda Sábato plantea que a la concentración de tierras que es posible observar hacia 1836 le sigue un proceso de subdivisión de la misma hacia 1864 y 1890, operado principalmente a través del mecanismo de la venta y de la herencia y que habría ido de la mano del auge de la producción ovina. Ello, no obstante, se da en el marco de la continuidad de explotaciones de carácter extensivo y de una cada vez menor distribución relativamente pareja de las superficies ${ }^{32}$. El análisis de Mariana Canedo sobre el partido de San Nicolás de los Arroyos a lo largo de dos siglos y medio revela esta tendencia a la fragmentación de la tierra, en una zona de antigua colonización, desde mucho antes ${ }^{33}$.

¿Cuál es la situación al sur del río Salado, en los territorios colonizados en la primera mitad del siglo XIX? (Ver cuadros 3 y 4).

Al observar los cuadros vemos que entre 1840 y 1860 se incorporan al dominio legal alrededor de 41.930,2 ha, al tiempo que el número de quienes tienen tierras pasa de 72 a 152. Analizando la relación que existe entre éstos, la cantidad de tierra que controlan y la extensión de las superficies, notamos que en la primera fecha el $71 \%$ de los que tienen tierras poseen el $22,4 \%$ de la misma en extensiones de hasta 8.099 ha mientras que, el $29 \%$ restante controla el $77,6 \%$ de la tierra en superficies de entre 8.100-40.500 ha. Vemos claramente la existencia de muchos productores asentados en superficies menores -según los parámetros de la zona- y unos pocos que controlan la mayor parte de la tierra del área, en posesión de terrenos de mayores dimensiones. 
CUADRO 3. DISTRIBUCION DE LA TIERRA SEGÚN SUPERFICIE DE LAS PROPIEDADES, 1840.

\begin{tabular}{|c|c|c|c|c|c|}
\hline $\begin{array}{l}\text { FRECUENCIA } \\
\text { HECTAREAS }\end{array}$ & $\begin{array}{l}\text { VOLUMEN } \\
\text { HECTAREAS }\end{array}$ & $\%$ & $\begin{array}{l}\mathrm{N}^{\circ} \\
\text { INDIVIDUOS } \\
\text { CON TIERRA }\end{array}$ & $\%$ & $\begin{array}{l}\text { SUPERFICIE } \\
\text { MEDIA HA }\end{array}$ \\
\hline $0-2669$ & 43091.9 & 7.3 & 28 & 39 & \multirow{3}{*}{2591.4} \\
\hline $2700-5399$ & 62612.1 & 10.7 & 19 & 26.4 & \\
\hline $5400-8099$ & 26459.3 & 4.4 & 4 & 5.6 & \\
\hline $8100-10799$ & 44136.9 & 7.4 & 5 & 7 & \\
\hline $10800-13499$ & 44800.8 & 7.5 & 4 & 5.6 & \\
\hline $13500-16199$ & 13770 & 2.3 & 1 & 1.4 & \\
\hline $16200-18899$ & 16200 & 2.7 & 1 & 1.4 & \\
\hline $18900-21599$ & 40932 & 6.9 & 2 & 2.6 & \\
\hline $21600-24299$ & 65781.6 & 11.2 & 3 & 4.1 & \\
\hline $24300-26999$ & $\ldots$ & -- & $\ldots$ & $\cdots$ & 21901.3 \\
\hline $27000-29699$ & $\ldots$ & - & $\ldots$ & -- & \\
\hline $29700-32399$ & 30240 & 5.1 & 1 & 1.4 & \\
\hline $32400-35099$ & $\ldots$ & $\ldots$ & $\ldots$ & - & \\
\hline $35100-37799$ & $\ldots$ & $\ldots$ & $\ldots$ & -- & \\
\hline $37800-40499$ & 38124 & 6.5 & 1 & 1.4 & \\
\hline 40500 & 165942 & 28 & 3 & 4.1 & \\
\hline TOTAL & 592090.6 & 100 & 72 & 100 & \\
\hline
\end{tabular}

Nota. $12.616,8$ ha corresponden a la Sociedad formada por Manuel Arroyo, Bernardo Ocampo y Julián Segundo Agujero. 20.250 ha corresponden a la Sociedad conformada por los hermanos Diego, Lorenzo y Miguel Agüero.

1496.1 ha no incluidas en el cuadro son propiedad del Estado.

Hay 5 terrenos en los que al parecer se subregistran herederos.

En el caso de 2 terrenos, al no especificarse qué superficie de los mismos se debia adjudicar a cada heredero, se dividió el área total del mismo por el número de herederos consignados.

Hay 1 terreno en el que fueron considerados dos los herederos a quienes se le traspasaba, por ausencia total de datos al

respecto.

De 1 de los terrenos incluidos en este cuadro poseemos información sólo hasta 1830 . Por falta de información cercana a la década de 1840 no se tomaron en consideración 13 terrenos.

Hay 2 terrenos sin superficie especificada y 1 sin fecha.

No se tomó en consideración 1 terreno que no está claro si se concedió y 1 objeto de conflicto, sin resolución final. Fuentes. Mensuras Antiguas al sur del Salado. Duplicados de mensuras del Partido de Dolores, Castelli, Pila, Tordillo, General Guido y General Lavalle. Libro de enfiteusis 1825 . 1840. Registro de arrendamientos y enfiteusis-ventas 1818 1838 (AHGyC). Legajos Sección Escribania Mayor de Gobierno (AHPBA).

Si observamos ahora el mismo fenómeno veinte años después, hacia 1860 , vemos que el porcentaje de individuos que poseen hasta 8.099 ha alcanza el $88,5 \%$ y que la tierra que controlan representa el 38,6\% del total de la misma. El 11,5\% de individuos restante, por su parte, tiene ahora en sus manos el $61,4 \%$ de la superficie de la zona. Estas cifras nos están indicando que el número de aquelios pequeños poseedores se ha incrementado al tiempo que lo ha hecho la cantidad de tierra que controlan. El aumento de la superficie en sus manos puede ser el resultado de la incorporación de nuevos campos al dominio legal, pero es también producto de 
CUADRO 4. DISTRIBUCIÓN DE LA TIERRA SEGƯN SUPERFICIE DE LAS

PROPIEDADES, 1860.

\begin{tabular}{|c|c|c|c|c|c|}
\hline $\begin{array}{l}\text { FRECUENCIA } \\
\text { HECTAREAS }\end{array}$ & $\begin{array}{l}\text { VOLUMEN } \\
\text { HECTAREAS }\end{array}$ & $\%$ & $\begin{array}{l}\mathrm{N}^{\circ} \text { INDIVIDUOS } \\
\text { CON TIERRA }\end{array}$ & $\%$ & $\begin{array}{l}\text { SUPERFICIE } \\
\text { MEDIA HA } \\
\end{array}$ \\
\hline $0-2669$ & 88140.4 & 14 & 98 & 64.4 & \multirow{3}{*}{1800.6} \\
\hline $2700-5399$ & 76076.9 & 12 & 24 & 15.6 & \\
\hline $5400-8099$ & 78868.6 & 12.6 & 13 & 8.5 & \\
\hline $8100-10799$ & 34182 & 5.3 & 4 & 2.6 & \multirow{14}{*}{22996.1} \\
\hline $10800-13499$ & 12616.8 & 1.9 & 1 & 0.7 & \\
\hline $13500-16199$ & - & $\ldots$ & $\cdots$ & - & \\
\hline $16200-18899$ & 34020 & 5.3 & 2 & 1.4 & \\
\hline $18900-21599$ & 20250 & 3.1 & 1 & 0.7 & \\
\hline $21600-24299$ & 88693.8 & 14 & 4 & 2.6 & \\
\hline $24300-26999$ & $\ldots$ & - & $\ldots$ & $\ldots$ & \\
\hline $27000-29699$ & $\cdots$ & $\ldots$ & $\ldots$ & $\ldots$ & \\
\hline $29700-32399$ & $\ldots$ & $\ldots$ & $\ldots$ & $\cdots$ & \\
\hline $32400-35099$ & $\ldots$ & - & $\ldots$ & -- & \\
\hline $35100-37799$ & 72507.8 & 11.5 & 2 & 1.4 & \\
\hline $37800-40499$ & 41589.5 & 6.5 & 1 & 0.7 & \\
\hline 40500 & 87075 & 13.8 & 2 & 1.4 & \\
\hline TOTAL & 634020.8 & 100 & 152 & 100 & \\
\hline
\end{tabular}

Nota. 12,616,8 ha corresponden a la Sociedad formada por Manuel Arroyo, Bernardo Ocampo y Julián Segundo Agüero. 20.250 ha corresponden a la Sociedad conformada por los hermanos Diego, Lorenzo y Miguel Agüero.

$35.230,3$ ha corresponden a la Sociedad integrada por Martínez de $\mathrm{Hoz}$ e hijos.

14.96,1 ha no incluidas en el cuadro son propiedad del Es. tado. $2.281,3$ ha en poder de particulares (incluidas en el cuadro) son de propiedad pública.

Hay 7 terrenos en los que al parecer se subregistran herede. ros.

En el caso de 5 terrenos, al no especificarse qué superficie de los mismos se debía adjudicar a cada heredero, se dividió el área total del mismo por el número de herederos consignados.

Hay 3 terrenos en los que fueron considerados dos los here- deros a quienes se les traspasaba, por ausencia total de datos al respecto.

De 1 de los terrenos incluidos en este cuadro poseemos información sólo hasta 1830 y de 2 sólo hasta 1840 . Por falta de información cercana a la década de 1860 no se tomaron en consideración 13 terrenos.

Hay 3 terrenos sin superficie especificada y 1 sin fecha.

No se tomó en consideración 1 terreno que no está claro si se concedió y 1 objeto de conflicto, sin resolución final.

Fuentes. Mensuras Antiguas al sur del Salado. Duplicados de mensuras del Partido de Dolores, Castelli, Pila, Tordillo, General Guido y General Lavalle. Libro de enfiteusis 1825 . 1840. Registro de arrendamientos y enfiteusis-ventas 1818 1838 (AHGyC). Legajos Sección Escribanía Mayor de Gobierno (AHPBA).

un cierto proceso de fragmentación de la tierra. Si bien es posible advertir una tendencia a la subdivisión en las mayores propiedades, podemos ver que ésta se da principalmente en aquellas superficies de entre 2.700-5.399 ha, a favor de las de no más de 2.700 ha. Es decir, la fragmentación de las superficies (vía ventas y traspasos por herencia), es más evidente entre aquellas de menores dimensiones ${ }^{34}$ (Ver planos 4,5 y 6 ).

34 La información con que contamos, como ya apuntamos en los cuadros, no nos permite determinar en más de una oportunidad la manera en que se dividen los terrenos en poder de los herederos de algún poseedor. En estos casos hemos considerado que la partición se habría hecho al menos entre dos personas. Teniendo en cuenta esta cuestión podemos afirmar, entonces, que el proceso de fragmentación de los terrenos en la zona en estudio, durante la primera mitad del siglo XIX, debe haber sido mayor que el que aquí pudimos establecer. 
PLANO 4 - Dolores, 1830.

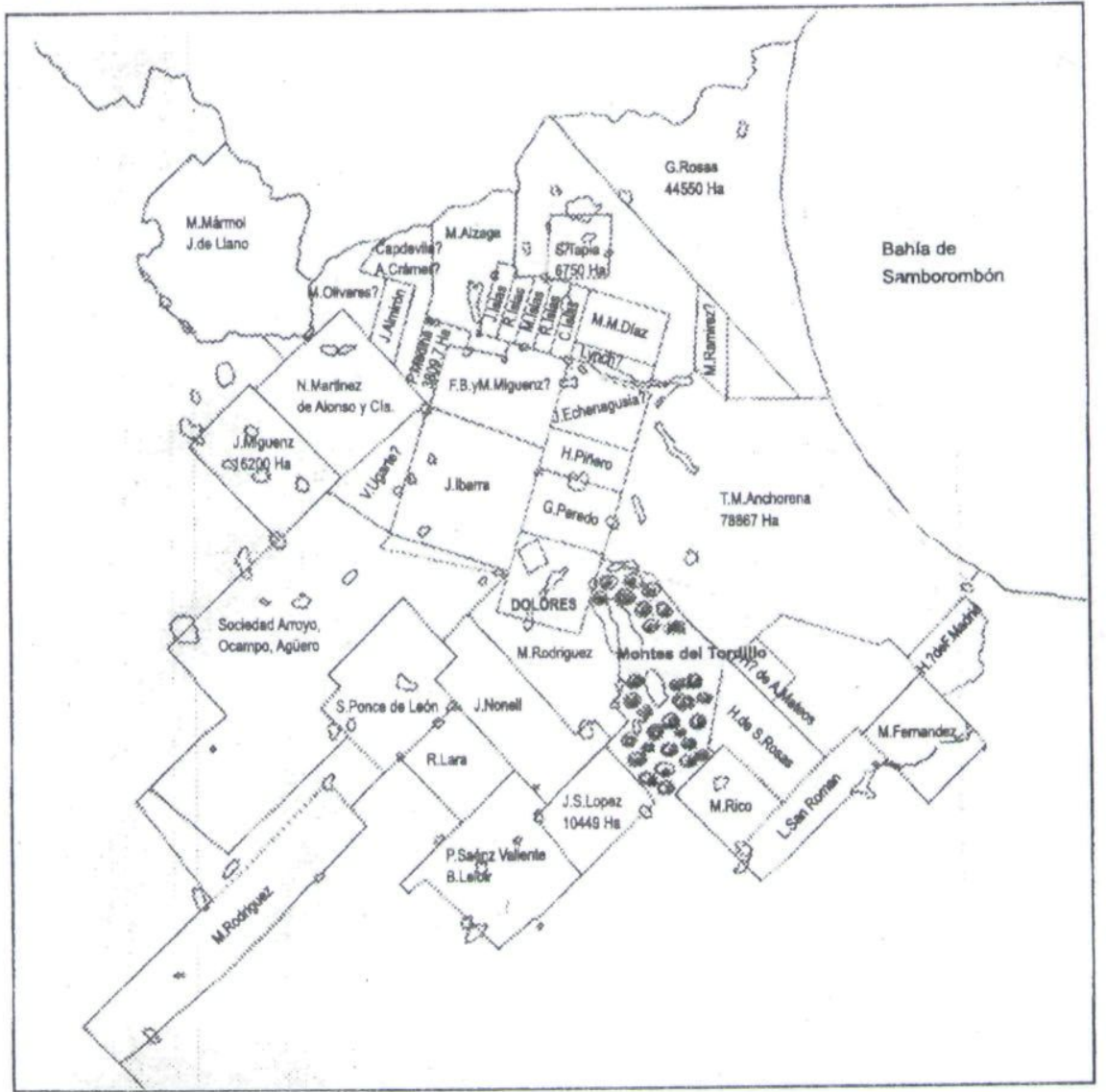

NOTA: Algunos terrenos, de los que poseemos información que fue analizada, no pudieron ser ubicados en el plano. Tampoco pudieron serlo los sobrantes públicos que se hallan dentro de los campos. Para más detalle ver los cuadros de sistematización de los datos en el Apéndice Generall.

-(H.de): Herederos de

Fuente: Elaboración propia en base a Duplicados de Mensuras de los partidos de Dolores, Castelli, Tordillo, Pila, Gral. Lavalle y Gral. Guido; Mensuras Antiguas al sur del Salado; Registro Gráfico de la Provincia de Buenos Aires de 1864 (AHGyC); Legajos varios de la sección Escribania Mayor de Gobiemo (AHPBA). 
PLANO 5 - Dolores, 1840.

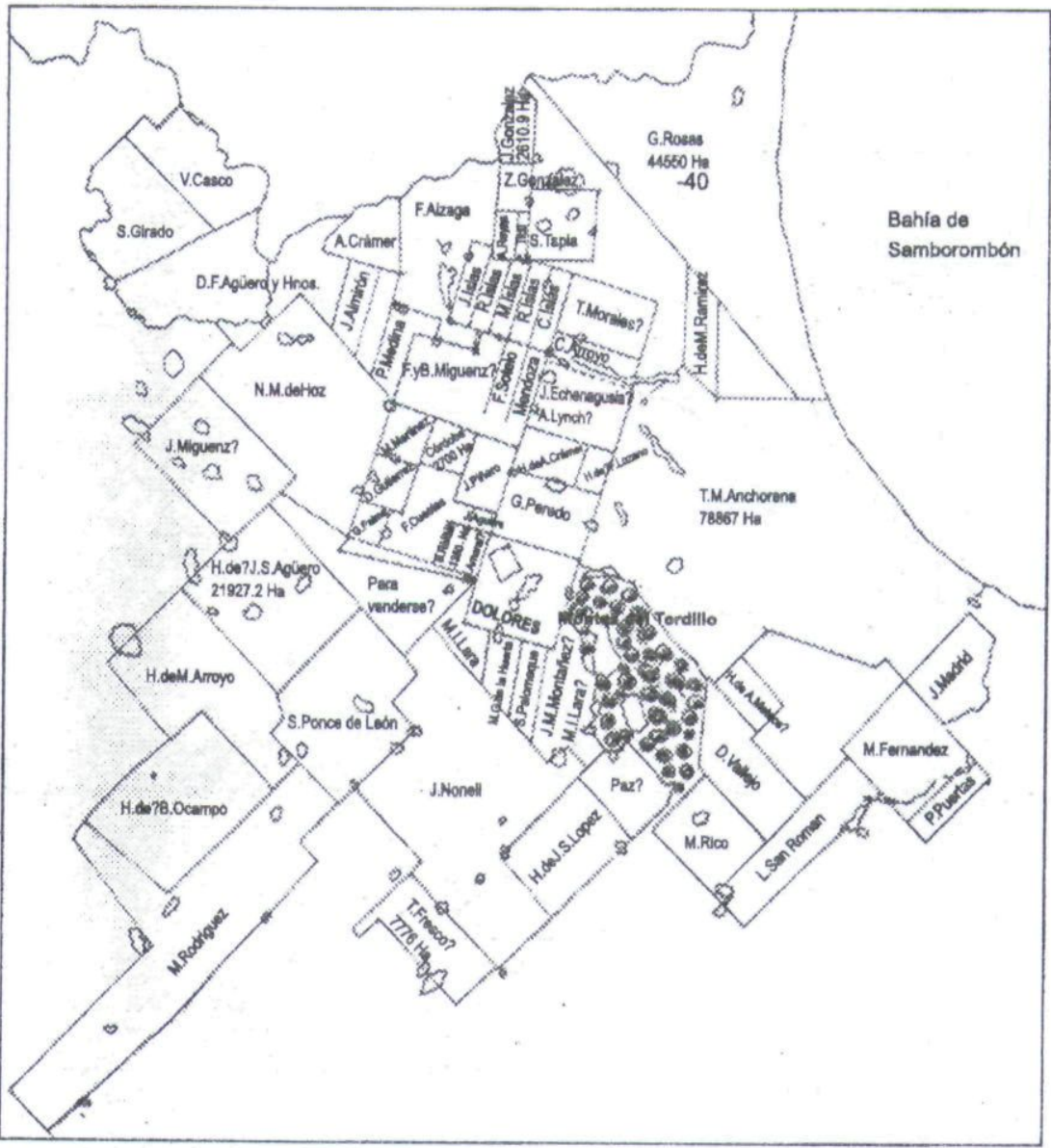

NOTA: * Algunos terrenos, de los que poseemos información que fue analizada, no pudieron ser ubicados en el plano. Tampoco pudieron serlo los sobrantes públicos que se hallan dentro de los campos. Para más detalle ver los cusdros de sistematización de los datos en el Apdndice Generall.

- $(-40)$ : La información que poseemos no llega hasta 1840

*(H.de): Herederos de

Fuente: Elaboración propia en base a Duplicados de Mensuras de los partidos de Dolores, Casteli, Tordillo, Plla, Gral. Lavalle y Gral. Guido; Mensuras Antiguas al sur del Saiado; Registro Gráfico de la Provincia de Buenos Aires de 1864 (AHGyC); Legajos varios de la sección Escribania Mayor de Gobierno (AHPBA). 


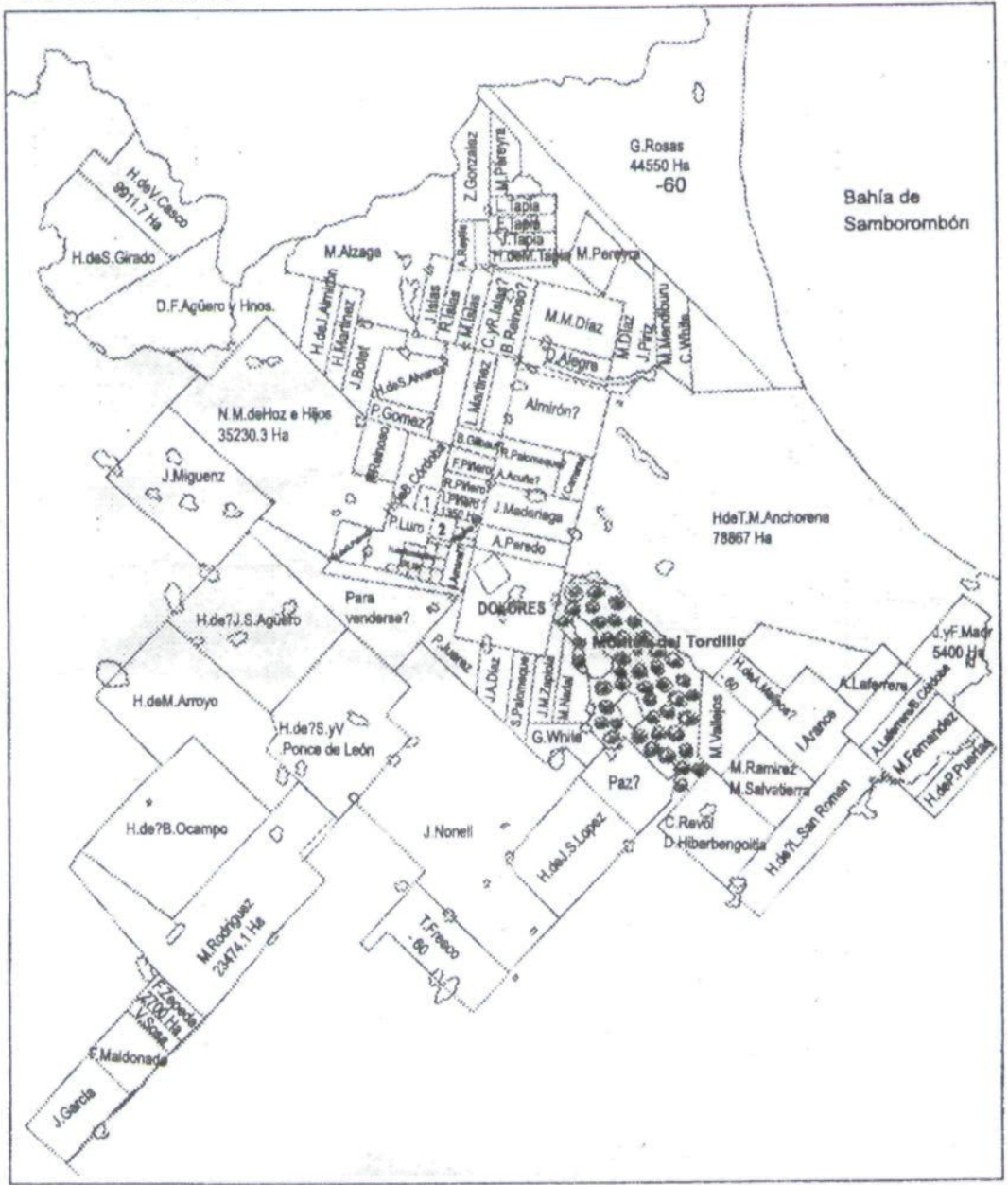

NOTA. "Avgunos terrenos, de los que poseemos información que fue snalizads, no pudluron ser ubicados en el plano. Tampoco pudieron serio los sobrantes públicos que se hallen dentro de los campos. Pera más detaite ver los cuadros des sistematización de los datos en ei Apdndice Generall. - (-60) La información que poseemos no llega hasta 1860

- (1): Terreno de Don Bonifacio Cordoba. Si bien la compra que realiza Don Bonifacio Córdoba a Don Fermin Cuestas en 1836 y 1854 es de 4050 Ha. (una legua y medis cundrada), el Contador Don Ratael de Maria solo toma en considersción $3375 \mathrm{Ha}$. (media iegue cuandrads).

- (2): Terreno de Don Juan de Dios Aquirre. Segùn las mensuras consultadas consta que Don Juan de Dios Aquirre comprs a Don Fermin Cuestas en 1839 media legua cuadrada de campo. En los plenos de los duplicadoe de mensura, en cambio, foura un cuarto de legua cuadrade. Tanto en el ceso 1 como on el 2 se considero media iegua cuadrads al analizar la informedion.

"(H.de) : Heredero de

Fuente: Elaboración propia en base a Duplicados de Mensuras de los partidos de Doiores, Castelli, Tordilio, Pila, Gral. Lavalle y Gral. Guido; Mensuras Antiguas al sur del Salado; Registro Gráfico de la Provincia de Buenos Aires de 1864 (AHGyC); Legajos varios de la sección Escribania Mayor de Gobiemo (AHPBA). 
Si observamos las superficies medias de los terrenos en manos de aquellos individuos que poseen hasta 8.099 ha $(2.591,4$ ha en 1840 y $1.800,6$ ha en 1860$)$ notamos que las mismas se acercan a las medidas correspondientes a una "suerte de estancia" (entre 1.875 ha y 2.025 ha). En un trabajo de Juan Carlos Garavaglia se señala que una suerte de estancia "permitiría a una familia medianamente constituida un pasar honorable como productor pecuario ${ }^{1 / 35}$.

A partir del análisis precedente volvamos a preguntarnos sobre una cuestión de fundamental importancia en el estudio que nos ocupa: ¿dónde están los 438 propietarios consignados en el censo de Dolores de 1836, mencionados en un trabajo anterior? ${ }^{36}$. Según lo que aquí podemos ver contabilizamos tan sólo 72 personas en 1840 y 152 en 1860 entre propietarios, enfiteutas y arrendatarios. Una explicación de este fenómeno puede hallarse en el hecho de que la ambigüedad de la condición de propietario, propia de un momento en el que el concepto mismo se halla en construcción, habría hecho que el censista englobe bajo esa condición tanto a los propietarios legales de la tierra como a los enfiteutas, arrendatarios y ocupantes de hecho ${ }^{37}$.

En el caso de una zona de antigua colonización como San Nicolás de los Arroyos, durante la primera mitad del siglo XIX, vemos que: hacia 1825 , el $58,1 \%$ de la superficie corresponde a parcelas menores a las 500 ha y de entre 500-999 ha desapareciendo, respecto a períodos anteriores, los terrenos de más de 3.000 ha y disminuyendo la superficie de los de entre 1.000-2.999 ha. Esto corresponde, según señala la autora, al momento de mayor intensidad en la fragmentación de las superficies. Para 1850, a su vez, se observa un incremento de las parcelas de entre 1.0001.499 ha y 1500-1999 ha en detrimento de, primero, las de 2.000-2.499 ha y, en segundo lugar, de las menores de 499 ha. Hay aquí, según se indica, un proceso de recomposición de algunos terrenos comprendidos entre las 500-999 ha y 1.000 $1.499 \mathrm{ha}^{38}$. Resulta evidente, al comparar estos datos con aquellos que presentamos para el sur del río Salado, la notable diferencia que existe en el tamaño de los campos en la primera mitad del siglo XIX: las mayores superficies no superan las 2.999 ha en San Nicolás mientras que, en el área que nos ocupa, llegan a las 40.500 ha. No obstante, es conveniente subrayar que en el área cuyo análisis abordamos al sur del río Salado, aunque en el marco de terrenos mucho más grandes que los del norte de la provincia, podemos distinguir distintos sectores de productores y propietarios. Destaquemos, a su vez, que en el marco de este proceso de traspaso y fragmentación de las tierras hay permanencias tanto en lo relativo a algunos poseedores de tierras como a las extensiones de las mismas, al menos entre 1830 y 1860 . Ejemplos en este sentido lo constituyen los casos de Gervasio Rosas, Tomás Anchorena, José

35 Garavaglia, 1998 (mimeo).

36 Nos referimos al estudio ya citado de Mascioli, 1999 :185-209. 
Miguens, Silverio Ponce de León, Lorenzo San Román, entre otros. Una situación similar a ésta se observa en Monte donde se instalan, hacia 1822, unas pocas familias (Antonio Dorna, Zenón Videla, la Sociedad Rosas Terrero) que mantienen las propiedades sin particiones hasta, al menos, $1850^{39}$.

Teniendo como marco general de la estructura de tenencia de la tierra la tendencia ya mencionada, veamos qué pasa específicamente con aquellas superficies otorgadas en enfiteusis, entre el momento de la concesión y el de la compra al Estado (Ver cuadros 5 y 6 ).

CUADRO 5. TIFRRAS CONCEDIDAS EN ENFITEUSIS, 1820-1830.

\begin{tabular}{|c|c|c|c|c|}
\hline $\begin{array}{l}\text { FRECUENCIA } \\
\text { HECTAREAS }\end{array}$ & $\begin{array}{l}\text { VOLUMEN } \\
\text { HECTAREAS }\end{array}$ & $\%$ & $N^{\circ}$ ENFITEUTAS & $\%$ \\
\hline $0-2669$ & 2657.2 & 1 & 1 & 5.3 \\
\hline $2700-5399$ & 16318.8 & 6.2 & 4 & 21 \\
\hline 5400-8099 & 16524 & 6.4 & 3 & 15.8 \\
\hline 8100-10799 & 36625.8 & 13.9 & 4 & 21 \\
\hline $10800-13499$ & 22410 & 8.5 & 2 & 10.5 \\
\hline $13500-16199$ & $\cdots$ & -- &.- & $\cdots$ \\
\hline $16200-18899$ & $\ldots$ & $\ldots$ & $\cdots$ & $\cdots$ \\
\hline $18900-21599$ & 20682 & 7.8 & 1 & 5.3 \\
\hline $21600-24299$ & 23382 & 8.9 & 1 & 5.3 \\
\hline $24300-26999$ & $\ldots$ & -- & $\cdots$ & $\ldots$ \\
\hline 27000-29699 & $\cdots$ & $\cdots$ & $\cdots$ & $\cdots$ \\
\hline $29700-32399$ & $\ldots$ & $\cdots$ & $\cdots$ & $\ldots$ \\
\hline $32400-35099$ & 66445.3 & 25.4 & 2 & 10.5 \\
\hline $35100-37799$ & + & $\cdots$ & $\ldots$ & $\ldots$ \\
\hline $37800-40499$ & -- & $\cdots$ & $\cdots$ & -- \\
\hline 40500 & 57267 & 21.9 & 1 & 5.3 \\
\hline TOTAL & 262312.1 & 100 & 19 & 100 \\
\hline
\end{tabular}

5.724 ha corresponden a un sobrante.

Hay dos terrenos cuyas superficies no están especificadas.

Fuentes. Mensuras Antiguas al sur del Salado. Duplicados de mensuras del Partido de Dolores, Castelli, Pila, Tordillo, Ceneral Guido y General Lavalle. Libro de enfiteusis 1825-1840. Registro de arrendamientos y enfiteusis-ventas 1818 -1838 (AHGyC). Legajos Sección Escribania Mayor de Gobierno (AHPBA).

En los cuadros es posible ver que, en las décadas de 1820 y 1830 , se conceden $262.312,1$ ha de tierras en enfiteusis a un total de 19 personas. En igual forma que la tendencia general ya observada sobre la distribución de la tierra en la zona, notamos una mayoría de enfiteutas $(73,6 \%$ ) que poseen sólo el $36 \%$ de la superficie concedida (en terrenos de hasta 13.499 ha) mientras que, el $64 \%$ restante de la tierra, está en manos del 26,4\% de los individuos, con posesiones de entre 13.500-40.500 ha.

39 Banzato, G., 1998: 37-64. 
CUADRO 6. PASAJE DE TIERRAS EN ENFTTEUSIS A DOMINIO PRIVADO, 1830.

\begin{tabular}{|c|c|c|c|c|}
\hline $\begin{array}{l}\text { FRECUENCIA } \\
\text { HECTAREAS }\end{array}$ & $\begin{array}{l}\text { VOLUMEN } \\
\text { HECTAREAS }\end{array}$ & $\%$ & $\begin{array}{l}\mathrm{N}^{\circ} \\
\text { PROPIETARIOS }\end{array}$ & $\%$ \\
\hline $0-2669$ & $\ldots$ & $\ldots$ & $\cdots$ & - \\
\hline $2700-5399$ & 4050 & 1.9 & 1 & 7.7 \\
\hline $5400-8099$ & 17064 & 7.9 & 3 & 23 \\
\hline $8100-10799$ & 30272.4 & 14.3 & 3 & 23 \\
\hline $10800-13499$ & 10800 & 5 & 1 & 7.7 \\
\hline $13500-16199$ & 14256 & 6.7 & 1 & 7.7 \\
\hline $16200-18899$ & 16902 & 7.9 & 1 & 7.7 \\
\hline $18900-21599$ & 20682 & 9.7 & 1 & 7.7 \\
\hline $21600-24299$ & - & - & $\ldots$ & - \\
\hline $24300-26999$ & - & - & $\ldots$ & $\ldots$ \\
\hline $27000-29699$ & - & - & $\ldots$ & $\ldots$ \\
\hline $29700-32399$ & $\cdots$ & - & $\ldots$ & $\ldots$ \\
\hline $32400-35099$ & $\cdots$ & - & - & $\cdots$ \\
\hline $35100-37799$ & $\ldots$ & - & $\cdots$ & $\ldots$ \\
\hline $37800-40499$ & $\ldots$ & - & $\ldots$ & $\ldots$ \\
\hline 40500 & 99792 & 46.6 & 2 & 15.5 \\
\hline TOTAL & 213818.4 & 100 & 13 & 100 \\
\hline
\end{tabular}

5.724 ha corresponden a un sobrante.

Hay un terreno cuya superficie no está especificada.

Fuentes. Mensuras Antiguas al sur del Salado. Duplicados de mensuras del Partido de Dolores, Castelli, Pila, Tordillo, General Guido y Generat Lavalle. Libro de enfiteusis 1825-1840. Registro de arrendamientos y enfiteusis-ventas 1818-1838 (AHCyC). Legajos Sección Escribania Mayor de Cobierno (AHPBA).

Del total de tierras otorgadas en enfiteusis pasan al dominio privado de 13 personas, por compra al Estado en la década de 1830, 213.818,4 ha. Si comparamos la estructura de tenencia de estas superficies, entre el momento en que son concedidas en enfiteusis y aquél en el que son adquiridas en propiedad, vemos que en esta última instancia hay una polarización acentuada entre una mayoría de propietarios $(84,5 \%$ ) que compran el $53,4 \%$ de la tierra en superficies de entre 2.700 21.599 ha y sólo dos individuos que tienen en sus manos el $46,6 \%$ de la superficie vendida, con posesiones de 40.500 ha. Es posible observar, entre los dos momentos, una tendencia a la concentración en favor de estas últimas superficies.

Un claro ejemplo de concentración de la tierra concedida en enfiteusis, vía transferencias entre particulares, lo constituye el caso de Don Juan Nonell. La superficie de 42.525 ha que este individuo compra al Estado el 29 de agosto de 1838 es adquirida previamente en enfiteusis por compra, a particulares, de tres terrenos linderos. Veamos esto con mayor detalle.

- En 1826 el Estado concede una superficie de 10.044 ha en enfiteusis a Don Ramón Lara. Este las transfiere a Don Andrés Burgos el 29 de mayo de 1833, quien a su vez las traspasa a su esposa Doña Saturnina Troncoso el 6 de mayo de 1838 . 
Este mismo año Don Juan Nonell compra a ésta el terreno en cuestión.

- El Estado concede en enfiteusis, a Don Eugenio Villanueva, un terreno de 23.382 ha en 1827 (?). Este lo vende el 14 de octubre de 1826 (?) a Don Pedro Sáenz Valiente y a Don Bartolomé Leloir. El 20 de junio de 1830 los compradores hacen la división del campo: 15.552 ha para Don Bartolomé Leloir y su esposa Doña Sebastiana Sáenz Valiente y 7.776 ha para Don Pedro Sáenz Valiente. El 18 de junio de 1831 los primeros venden, a Don Juan Nonell, 14.310 ha.

- En 1825 Don Julián Salomón vende un terreno que posee en enfiteusis (desconocemos la fecha y manera en que lo obtienel a la Sociedad Rural Argentina (17.631 ha) y a Don Juan Nonell (18.171 ha).

Es ésta la manera en que obtiene Don Juan Nonell la superficie de terreno que finalmente, en 1838, adquiere en propiedad por compra al Estado ${ }^{40}$.

Retomando lo planteado, entonces, vimos que la década de 1820 marca una inflexión respecto a los años anteriores debido al notable incremento de las transferencias entre particulares tanto de tierras privadas como de los derechos de usufructo sobre las públicas, a partir fundamentalmente de la venta. Esta situación, sumada al aumento del precio de la tierra desde entonces, se vincula con el auge que la producción pecuaria cobra en la campaña bonaerense y con la peculiar relación que ésta establece con el mercado internacional. La compra de tierras es, así, una inversión productiva que permite mantener los capitales ${ }^{4}$.

A partir entonces de 1820 el mecanismo más extendido para acceder a la tierra, en la zona en estudio, es el de la compra. Si bien subsisten todavía hacia fines de la década de 1850 algunas tierras públicas (otorgadas en arrendamiento unas, baldías otras) y la posibilidad de asentarse al interior de terrenos ya apropiados legalmente, el acceder a una parcela implica hacerlo prácticamente sólo a través de una operación mercantili².

Estos intercambios mercantiles entre particulares se dan mayormente entre personas al parecer sin lazos de parentesco. Algunos de ellos, incluso, no son del lugar sino que probablemente tienen su residencia en la ciudad de Buenos Aires e invierten en tierras en distintos puntos de la campaña. Es decir, la operatoria mercantil trasciende el ámbito puramente local.

Estas cuestiones nos remiten a la de la formación de un mercado de tierras, problemática tratada en algunos estudios sobre historia rural rioplatense. En lo que

40 Un caso de concentración de tierras concedidas en enfiteusis es también el de Don Tomás Manuel de Anchorena que suma, al campo de su propiedad, algunas superficies linderas que obtiene en enfiteusis. En este caso, no obstante, la adición de las mismas se da por sucesivos pedidos al Estado y no por compra a particulares.

41 Garavaglia, 1999 (mimeo).

42 Si bien no sabemos en qué medida es posible ocupar tierras sin derechos reconocidos, en la primera mitad del siglo XIX, recordemos lo ya expuesto sobre la implementación de un nuevo marco normativo por parte del Estado en este período. El concepto de propiedad privada que comenzaría a cobrar forma a partir de entonces habría conspirado contra la ocupación de hecho de las tierras. Para un tratamiento de esta cuestión remitimos al lector a los trabajos de Fradkin, 1997: 141-156; Gelman, 1997. 
respecta al período comprendido entre 1750-1826 Juan Carlos Garavaglia señala la existencia de éste de manera "imperfecta", por encontrarse en formación. Con ello quiere significar que "...sólo parcialmente los mecanismos de mercado rigen el acceso a la tierra" ${ }^{\prime 43}$. Mariana Canedo, en su estudio sobre el partido de San Nicolás de los Arroyos, ve esta tendencia a la formación del mismo durante el siglo XVIII a partir, fundamentalmente, de las operaciones mercantiles realizadas entre $1740 \mathrm{y}$ $1760^{44}$.

De esta manera podemos concluir que a partir fundamentalmente de 1820 y a medida que avanzamos en el siglo XIX el mecanismo de mercado se convierte, en la zona estudiada, casi en la única vía de acceso a la tierra. Ello no obstante la existencia, todavía hacia fines de 1850 , de una cierta oferta de tierra pública. La profundización de estas cuestiones, no obstante, conlleva la necesidad de establecer las características del mecanismo de formación de precios, información que no proporcionan las fuentes que manejamos ${ }^{45}$.

\section{Consideraciones finales}

Establecerse en la frontera habría sido una posibilidad al alcance de productores y propietarios con características diversas. Así, en el marco de un proceso de poblamiento dinámico tenemos, de un lado, el acceso al usufructo de la tierra; del otro, la apropiación legal de la misma y, en medio, la existencia de diversas alternativas entre las que los individuos pueden optar, de acuerdo a sus posibilidades. No habría habido, entonces, una única vía por transitar a lo largo del proceso de acceso a la tierra, sino que cada individuo habría recorrido su propio camino.

Las diversas alternativas mencionadas se enmarcan dentro de la combinatoria de una oferta estatal y privada de tierras entre las que señalamos la ocupación de hecho de la misma ya desde fines del siglo XVIII, la adquisición de derechos de usufructo mediante las concesiones en enfiteusis y arrendamiento en las décadas de 1820 y 1850 , y la obtención de la tierra en propiedad por compra al Estado o a algún particular. De esta manera ocupantes, enfiteutas, arrendatarios, subarrendatarios y propietarios son algunos de los actores del proceso colonizador en esta zona de "más allá" del Salado.

Tanto las tierras privadas como los derechos de usufructo sobre las públicas son objeto de traspasos entre particulares, de manera más intensa en la década de 1820 bajo las modalidades de la venta primero y la herencia después. Como pro-

43 Garavaglia, 1999 (mimeo).

44 Canedo, 2000.

45 Ver Levi, 1990. Para la zona norte del río Salado J.C. Garavaglia, en un estudio de 575 inventarios de establecimientos productivos, encuentra que entre 1751 y 1815 los precios de la tierra guardan relación no sólo con la producción agropecuaria sino también con la ubicación de la misma respecto a mercados, seguridad frente a ataques indigenas, existencia o no de aguadas, elcétera. Probablemente la consulta y el análisis de este tipo de documentación referida a los establecimientos productivos al sur del Salado nos permita en un futuro adentrarnos en la problemática del precio de la tierra. 
ducto de las sucesivas transferencias es posible observar una tendencia general a la división de las superficies (más evidente en aquellas de menores dimensiones), a la vez que un ligero proceso de concentración con relación a las tierras concedidas en enfiteusis y el caso de algunas parcelas que mantienen tanto su extensión como sus poseedores, al menos entre 1830 y 1860 . Así, tanto para 1840 como para 1860 , años en que analizamos la estructura de la propiedad, notamos la existencia de una mayoría de individuos ( $71 \%$ y $88,5 \%$ para ambas fechas respectivamente) que controlan relativamente poca tierra $(22,4 \%$ y $38,6 \%$ de la misma respectivamente) en superficies que, de acuerdo a los parámetros de la zona, podemos caracterizar como "chicas" y "medianas" (entre 0-8.099 ha). Estos coexisten, a su vez, con unos pocos ( $29 \%$ y $11,5 \%$ para 1840 y 1860 respectivamente) con poder sobre gran extensión de tierra $(77,6 \%$ y $61,4 \%$ de la superficie total para ambas fechas respectivamente) en parcelas de tamaños considerables (entre 8.100-40.500 ha).

Muchos productores y/o propietarios con poca tierra en parcelas "chicas" y "medianas" y unos pocos controlando "grandes" extensiones en poder de terrenos mucho mayores. Así, la imagen de la coexistencia de productores y propietarios diversos, que proporciona el análisis del proceso de acceso a la tierra, viene a corroborar lo que ya sabíamos a partir del estudio del empleo de la mano de obra en los diferentes establecimientos productivos. A manera de ejemplo podemos ilustrar esta diversidad mencionando situaciones tan diferentes como las que siguen: Tomás Anchorena conforma su propiedad conocida como "Las Víboras", de 78.867 ha, por compra de 21.600 ha en propiedad y 30.375 ha en enfiteusis a la testamentaría de Pedro Alcántara Capdevila, en 1830. A estas últimas suma luego unos sobrantes hasta completar un total de 57.267 ha que en 1838 compra al Estado. Recordemos que en su establecimiento aparecen censados, en 1836, 17 personas entre capataz, peones, esclavos y agregados. Situaciones similares son las de otros grandes productores de la zona, cuyos nombres seguramente no pasarán inadvertidos al lector. Tal es el caso de Marcos Miguens, Clemente López Osornio, Gervasio Rosas, Félix y Martín Alzaga, Julián Segundo Agüero, Marcelino Rodríguez, Narciso Martínez de Hoz, entre otros. Diferente es la situación de Santiago Tapia que se convierte en propietario de 8.100 ha que compra al Estado en 1810, tras haberlas denunciado un año antes. En este caşo sabemos que, en 1836, aparecen censados Sebastiana Naranjo (su esposa?) y algúnos de sus hijos (Francisca, Marcos y Ventura) junto a 2 esclavos, 2 peones y un agregado con su familia. Otro caso es el de Bonifacio Córdoba, quien compra a Fermín Cuestas 2.700 y 1.350 ha en 1836 y 1852 , respectivamente. A este productor lo hallamos censado en 1836 junto a su esposa Antonia Cardoso y a sus hijos Dolores, Eufemia, Gregorio y Ursula. Benito Rondanina, en cambio, es dueño de 675 ha por compra que, en 1857, realiza a Fermín Cuestas. Resulta interesante saber que este individuo es censado, en 1836, como peón en una estancia de Postrera. No sería extraño suponer, de acuerdo a lo que se ha planteado para otras zonas de la campaña, que continuara conchabándose aún después de haber 
adquirido una parcela de tierra en propiedad.

Con relación al mencionado estudio realizado en base a fuentes censales de la primera mitad del siglo XIX, es necesario remarcar la generalización que se hace en éstas de la condición de propietario a todos aquellos individuos que encabezan unidades censales en 1836. Dicha condición, mucho más amplia de lo que el análisis de la documentación sobre tierra nos muestra, estaría reflejando la ambigüedad de un concepto en construcción, ajeno por aquel entonces a las connotaciones que más tarde adquiriría.

Pero volvamos por un momento hacia atrás y reconsideremos aquellos aspectos que habrían caracterizado el proceso colonizador de otras zonas de la campaña bonaerense en distintas etapas. Tomando el caso de la zona fronteriza comprendida por los actuales partidos de Chascomús, Monte y General Paz entre fines del período colonial y principios del siglo XIX, y el de San Nicolás de los Arroyos entre los siglos XVII y XIX, vemos que si bien la apropiación legal de la tierra difiere en ambas zonas en cuanto a modalidades y épocas (en San Nicolás se da en el siglo XVII a partir de la concesión de tres mercedes reales que abarcan la superficie total del partido, mientras que en Chascomús, Monte y General Paz, se opera entre fines del siglo XVIII y principios del XIX a partir de mercedes reales, moderada composición, compras al Estado, donaciones y enfiteusis), en ambos casos ésta suele ser precedida por la ocupación de la tierra. Y en este punto San Nicolás presenta la particularidad de que dicha ocupación se da, de manera exclusiva, al interior de parcelas ya apropiadas legalmente. De esta manera, tanto en una zona de antigua colonización como en aquellas de frontera, existen distintos momentos en el proceso de acceso al usufructo y apropiación legal de la tierra. Cruzando el Salado e instalándonos en la zona del Arroyo Azul, en cambio, observamos la importancia que tienen aquí las donaciones condicionadas por parte del Estado, hacia principios de la década de 1830. Como ya señalamos, la relevancia que el área tiene en lo que respecta al contacto con las sociedades indígenas, podría explicar esta situación.

Otra característica común que comparten las áreas mencionadas (San Nicolás de los Arroyos y Chascomús, Monte y General Paz) es la del predominio del traspaso de la tierra a partir fundamentalmente de la venta y la herencia, aunque ello no excluye otras modaiidades en el caso de San Nicolás y Dolores (donaciones, dote, adjudicación, entre otras). Estas transferencias, que tanto para el caso de San Nicolás como para el de Dolores sabemos se incrementan hacia la década de 1820 y disminuyen hacia la de 1840, generan procesos tanto de parcelación como de concentración y hasta de mantenimiento y recomposición de las superficies, dando con ello lugar a la existencia de parcelas de tamaños variados.

Si bien, como ya dijimos, en la primera mitad del siglo XIX algunas cosas empiezan a cambiar respecto a etapas anteriores (fundamentalmente los estudios señalan la aparición de algunos "grandes productores" y la instauración de una nueva normatividad por parte de un Estado provincial en formación) pudimos ver que 
todavía es posible seguir advirtiendo la presencia de productores y propietarios diversos y de distintas formas y etapas con relación al acceso a la tierra. Y ello resulta de mayor relevancia si tenemos presente que estamos hablando de Dolores, una zona que por su ubicación geográfica y la época de colonización podría pensarse como claro exponente de la denominada "expansión ganadera", con sus grandes latifundios en poder de unos pocos propietarios.

Queda de esta manera esbozada una imagen más acabada sobre las características que asume el proceso colonizador al sur del río Salado en la primera mitad del siglo XIX. Un proceso sin duda complejo cuyo desentrañamiento nos llevará, proximamente, a indagar otros aspectos.

Recibido 15/05/02

Evaluado 03/06/02

\section{Resumen \\ Caminos de acceso al usufructo y propiedad legal de la tierra en la frontera bonaerense. \\ Dolores, 1798-1860.}

El presente trabajo tiene como objetivo contribuir a la caracterización del mundo rural rioplatense de la primera mitad del siglo XIX a partir del análisis del proceso colonizador de un área al sur del río Salado de la actual provincia de Buenos Aires. Para ello circunscribimos espacial y temporalmente nuestro estudio al partido de Dolores (más amplio territorialmente que el actual), entre 1798 y 1860. La caracterización del proceso de acceso al usufructo y a la propiedad legal de la tierra en la zona, sumado al análisis socio-demográfico de la población (realizado en otra oportunidad) aspiran a ser un aporte en ese sentido.

Lejos de constituir el caso estudiado un ejemplo paradigmático de la "expansión ganadera" operada en el marco de grandes latifundios en poder de unos pocos propietarios (imagen tal vez esperable al referirnos a un área al sur del Salado y en pleno proceso de colonización entre fines del siglo XVIII y principios del XIX), la complejidad y el dinamismo del proceso estudiado quedan en evidencia: usufructuar y apropiarse legalmente de la tierra en Dolores supone el posible tránsito, de productores con posibilidades y necesidades diferentes, a través de diversos caminos. La reconstrucción del proceso, a su vez, nos permite hacer comparaciones con los ocurridos en otras zonas y en otros momentos, contribuyendo así a explicar la ocupación del espacio pampeano en una perspectiva diacrónica.

Palabras claves: proceso colonizador - frontera - tierra 


\title{
Summary \\ Different ways to access to the usufruct and to the legal property of land in the bo- naerense borders. Dolores, 1798-1860.
}

The aim of this paper is to contribute to the characterization of the rioplatense rural world in the first half of the nineteenth century by the analysis of the colonization process in an area situated in the south of Salado River in present Buenos Aires province. We circumscribe our work in time and space focusing on Dolores District (with a larger surface than the present one) between 1789 and 1860. The characterization of the process to access to the usufruct and to the legal property of land in the area added to the social and demographical analysis of the population (Mascioli, 1999) expects to be a contribution to the above mentioned topic.

The case studied is far from being a paradigmatic example of the "expansion of livestock breeding" that would have taken place in latifundia owned by a few owners (a familiar image when we talk about an area situated in the south of Salado River in times of the colonization process between the end of the eighteenth century and the beginning of the nineteenth century). The complexity and dynamism of the process studied are evident: to usufruct and to access to the legal property of land in Dolores implies the possibility to transit different ways for producers with different possibilities and necessities. Besides, the reconstruction of the process will let us compare it with others that took place in other lands and time, in order to explain the occupation of the pampeano surface in a diachronic perspective.

Key words: colonization process - borders - land

\begin{abstract}
Apéndice.
Detalle y descripción de las fuentes empleadas Mensuras Antiguas al sur del Salado y Duplicados de Mensuras. En ciertas ocasiones en que un terreno es objeto de alguna transferencia, ya sea ésta del Estado a un particular o entre particulares, se lo delimita a partir de una operación de medición y amojonamiento. Las mensuras Antiguas al sur del Salado y los Duplicados de Mensuras son las que contienen esa información. Estas operaciones de mensura son realizadas por un agrimensor propuesto por el interesado y aprobado por el Departamento Topográfico (posteriormente Departamento de Ingenieros) y en presencia de los linderos, quienes son previamente citados mediante nota escrita. Una vez finalizada, y habiendo firmado los presentes en conformidad o no, es remitida al mencionado Departamento para su observación. Este puede ordenar su aprobación 0 indicar las rectificaciones que deben hacerse. Las Mensuras Antiguas contienen información sobre el tipo de transferen-
\end{abstract}


cia de que se trata (la modalidad, la fecha y entre quiénes se realiza), la ubicación del terreno (indicando sus dimensiones) y los linderos. Se acompañan, a su vez, de un plano del campo en cuestión en el que se señala su superficie, los linderos y, eventualmente, la existencia de algunos montes y lagunas.

Los Duplicados de Mensuras, por su parte, contienen dos clases de información. Por un lado, hay un extracto en el que se detalla la manera en que el terreno en cuestión ha sido transferido en distintos momentos. Así, se proporcionan datos sobre la modalidad de traspaso y las personas intervinientes, la fecha de realización de la operación, la superficie de terreno implicada, los linderos y, eventualmente, el precio y la forma de pago. Por otro, se detalla la operación de mensura desde el punto de vista técnico. A los fines de nuestro trabajo esta segunda sección nos aporta invalorable información tanto sobre las características físicas de los terrenos como sobre los puestos y/o poblaciones ya que, a medida que el agrimensor va realizando su trabajo, describe el suelo y el clima del lugar y menciona los puestos, poblaciones, pulperías, que halla a su paso. Al igual que en el caso de las Mensuras Antiguas, un plano del terreno en cuestión acompaña cada Duplicado de Mensura. En ellos encontramos información variable entre unos y otros que incluye el dibujo del terreno y sus dimensiones, los linderos y, en ocasiones, referencias a montes, lagunas, pajonales, caminos, puestos y/o poblaciones, etc.

Legajos de la Sección Escribanía Mayor de Gobierno del AHPBA. Esta documentación contiene el registro de solicitud de tierras al Estado por parte de los particulares (bajo diferentes modalidades), la concesión de las mismas, los pedidos de permiso para la transferencia de las tierras en enfiteusis, las mensuras y planos de los terrenos en algunos casos y la mención y eventualmente el desarrollo de los conflictos suscitados en torno a estas cuestiones.

Libro de enfiteusis 1825-1840 y Registro de arrendamientos y enfiteusis-ventas 1818-1838. Estos libros contienen el registro de aquellas concesiones de tierras en enfiteusis y arrendamiento (beneficiarios y fecha), el canon a pagar y los momentos en que ésto se efectiviza y las transferencias de que son objeto estos terrenos.

A partir de los datos brindados por las distintas fuentes a las que hemos hecho referencia, elaboramos una serie de cuadros sobre las transferencias de la tierra hasta 1860. En ellos detallamos la fecha en que se realiza la transferencia del terreno, bajo qué modalidad (venta, herencia, donación, enfiteusis, etc.), quién es el otorgante y quién el adquisidor, las dimensiones del terreno, el precio, el año de la mensura y el nombre del agrimensor, la fecha de aprobación de la misma, las características físicas del terreno y otras observaciones generales que complementan la información anterior.

A su vez, con estos datos y tomando como base el Registro Gráfico de la provincia de Buenos Aires de 1864 y los planos de mensura de cada terreno, reconstruimos los planos topográficos del partido en distintos momentos $(1830,1840$ y 1860). 


\section{Referencias Bibliográficas}

- AA.VV. (1997), "Continuidades y rupturas en la primera mitad del siglo XIX en el Río de La Plata (mundo rural, Estado, cultura)". En Anuario del IEHS, Tandil, $\mathrm{N}^{\circ} 12$.

- AVELLANEDA, N. (1865), La tierra pública. Estudio sobre las leyes de tierras públicas, Buenos Aires.

- BANZATO, G. (mimeo 1997), "Estrategias de ocupación y acceso a la propiedad legal de la tierra en la campaña bonaerense. Chascomús, Ranchos y Monte, 1779-1850". Ponencia presentada en las VI Jornadas Interescuelas Departamentos de Historia, La Pampa.

- BANZATO, G. (1998), "Ocupantes y propietarios legales en la región nordeste del río Salado. Chascomús, Ranchos, y Monte entre 1779 y 1850 ”. En: GIRBAL BLACHA, N. y M. Valencia (coord.), Agro, tierra y política. Debates sobre la historia rural de Argentina y Brasil, La Plata, Editorial de la UNLP.

- CANEDO, M. (2000), Propietarios, ocupantes y pobladores. San Nicolás de los Arroyos, 1600-1860, Mar del Plata, Imprenta de la UNMdP.

- CÁRCANO, M. A. (1972), Evolución histórica del régimen de la tierra pública, Buenos Aires, Eudeba.

- CARRETERO, A. (1972), La propiedad de la tierra en la época de Rosas, Buenos Aires, El Coloquio.

- CONI, E. (1927), La verdad sobre la enfiteusis de Rivadavia, Buenos Aires, Imprenta de la Universidad.

- DORCAS BERRO, R. (1939), Nuestra Señora de los Dolores, La Plata, publicaciones del Archivo Histórico de la provincia de Buenos Aires.

- FRADKIN, R. (mimeo 1991), "Labradores del instante, arrendatarios eventuales'. El arriendo rural en Buenos Aires a fines del siglo XVIII". Ponencia presentada en las III Jornadas Interescuelas Departamentos de Historia, Buenos Aires.

- FRADKIN, R. (1993), "Producción y arrendamiento en Buenos Aires del siglo XVIII: la hacienda de la Chacarita (1779-84)". Fradkin, R. (comp.), La historia agraria del Río de la Plata colonial. Los establecimientos productivos, Buenos Aires, CEAL, v. II.

- FRADKIN, R. (1995), "Según la costumbre del pays': costumbre y arriendo en Buenos Aires durante el siglo XVIII". Boletín del Instituto de Historia Argentina y Americana 'Dr. Emilio Ravignani', Buenos Aires, UBA, N 11.

- FRADKIN, R. (1997), "Entre la ley y la práctica: la costumbre en la campaña bonaerense de la primera mitad del siglo XIX". Anuario del IEHS, Tandil, $\mathrm{N}^{\circ}$ 12.

- GARAVAGLIA, J. C. (1995), "Precios de los productos rurales y precios de la tierra en la campaña de Buenos Aires, 1700-1826". Boletín del Instituto de Historia Argentina y Americana 'Dr. Emilio Ravignani', Buenos Aires, UBA, N ${ }^{\circ}$ 11. 
- GARAVAGLiA, J. C. (mimeo 1999), "La economía rural de la campaña de Buenos Aires vista a través de sus precios (1754-1852)". Ponencia presentada en la Reunión de la Red de Estudios Rurales, Buenos Aires.

- GARAVAGLIA J. C. (mimeo 2000), "La propiedad de la tierra en la región pampeana: algunos aspectos de su evolución histórica (1730-1863)". Ponencia presentada en las XVII Jornadas Interescuelas Departamentos de Historia, Tucumán.

- GELMAN, J. (1997), Un funcionario en busca del Estado. Pedro Andrés García y la cuestión agraria bonaerense, 1810-1822, Quilmes, Universidad Nacional de Quilmes.

- INFESTA, M. E. y M. VALENCIA, (1987), "Tierras, premios y donaciones. Buenos Aires, 1830-1860". Anuario del IEHS, Tandil, $\mathrm{N}^{\circ} 2$.

- INFESTA, M. E. (1993), "La enfiteusis en Buenos Aires (1820-1850)". En BONAUDO, M. y A. PUCCIARELLI (comps.), La problemática agraria. Nuevas aproximaciones, Buenos Aires, CEAL, v.I.

- INFESTA, M. E. (1997), "Avance territorial y oferta de tierras públicas. Buenos Aires, 1810-1850". Anuario del IEHS, Tandil, $\mathrm{N}^{\circ} 12$.

- IRIGOIN, A. (mimeo 2000), "La expansión ganadera en la campaña de Buenos Aires: las consecuencias de la inflación y el uso del papel moneda en la financiación del déficit fiscal, 1820-1860". Ponencia presentada en las XVII Jornadas Interescuelas Departamentos de Historia, Tucumán.

- LANTERI, M. S. (mimeo 2000), Poder, poblamiento y relaciones interétnicas en el sur bonaerense. Las donaciones de tierra en el Arroyo Azul en la primera mitad del siglo XIX. Tesis de Licenciatura presentada en la Facultad de Humanidades, Universidad Nacional de Mar del Plata.

- LEVI, G. (1990), La herencia inmaterial. La historia de un exorcista piamontés del siglo XVII, Madrid, Nerea.

- MASCIOLI, A. (1999), "Población y mano de obra al sur del Salado. Dolores en la primera mitad del siglo XIX". En Fradkin, R., M. Canedo y J. Mateo (comps.), Tierra, población y relaciones sociales en la campaña bonaerense (siglos XVIII y XIX), Mar del Plata, Imprenta de la UNMdP.

- MASCIOLI, A. (mimeo 1999), Propietarios y productores de la frontera bonaerense, 1798-1860. Tesis de Maestría, Universidad Internacional de Andalucía, Sede Iberoamericana Santa María de La Rábida, Huelva, España.

- MATEO, J. (1999), "Pequeños ranchos sobre la pampa. La población en la colonización de la frontera de Buenos Aires. San Salvador de Lobos, 1810-1869", En: FRADKIN, R., M. CANEDO y J. MATEO (comps.), Tierra, población y relaciones sociales en la campaña bonaerense (siglos XVIII y XIX), Mar del Plata, Imprenta de la UNMdP.

- ODDONE, J. (1967), La burguesía terrateniente argentina, Buenos Aires, Ediciones Libera.

- OTS CAPDEQUI, J. (1945), Manual de Historia del derecho español en las 
Indias y del derecho propiamente indiano, Buenos Aires, Losada.

- RONCORONI, A. (1967), Historia del Municipio de Dolores, Dolores, editado por la Municipalidad de Dolores.

- SÁBATO, H. (1989), Capitalismo y ganadería en Buenos Aires. La fiebre del lanar 1850-1890, Buenos Aires, Sudamericana.

- VALENCIA, M. (1986), "Los arrendamientos públicos en la provincia de Buenos Aires (1857-1872)". Estudios sobre la provincia de Buenos Aires, La Plata, Archivo Histórico de la provincia de Buenos Aires, v.I. 